OPEN ACCESS

Edited by:

Philippe Juneau,

Université du Québec à Montréal,

Canada

Reviewed by:

Tse-Min Lee,

National Sun Yat-sen University,

Taiwan

Vijay Pratap Singh,

University of Allahabad, India

*Correspondence:

Ha-il Jung

hi255@korea.k

Jinwook Lee

JL425@cau.ac.kr:

j1425@cornell.edu

Specialty section:

This article was submitted to

Plant Abiotic Stress,

a section of the journal

Frontiers in Plant Science

Received: 23 July 2020 Accepted: 29 October 2020

Published: 30 November 2020

Citation:

Jung $H-i$, Lee B-R, Chae M-J, Lee E-J, Lee T-G, Jung G-B, Kim M-S and Lee J (2020) Ascorbate-Mediated

Modulation of Cadmium Stress Responses: Reactive Oxygen Species and Redox Status in Brassica napus.

Front. Plant Sci. 11:586547.

doi: 10.3389/fp/s.2020.586547

\section{Ascorbate-Mediated Modulation of Cadmium Stress Responses: Reactive Oxygen Species and Redox Status in Brassica napus}

\author{
Ha-il Jung ${ }^{1 *}$, Bok-Rye Lee ${ }^{2}$, Mi-Jin Chae', Eun-Jin Lee', Tae-Gu Lee', Goo-Bok Jung ${ }^{3}$, \\ Myung-Sook Kim ${ }^{1}$ and Jinwook Lee ${ }^{4 *}$ \\ 1 Division of Soil and Fertilizer, National Institute of Agricultural Sciences, Rural Development Administration, Wanju, \\ South Korea, ${ }^{2}$ Department of Animal Science, Institute of Agricultural Science and Technology, College of Agriculture \\ and Life Science, Chonnam National University, Gwangju, South Korea, ${ }^{3}$ Division of Climate Change and Agroecology, \\ National Institute of Agricultural Sciences, Rural Development Administration, Wanju, South Korea, ${ }^{4}$ Department of Plant \\ Science and Technology, Chung-Ang University, Anseong, South Korea
}

The role of ascorbate (AsA) in antioxidant defense system-associated resistance to cadmium $(\mathrm{Cd})$ in oilseed rape plants has not yet been clearly demonstrated. The present study investigated the critical role of exogenous AsA on the physiological and biochemical responses of reactive oxygen species (ROS) and antioxidant scavenging defense systems in oilseed rape (Brassica napus L. Cv. Tammi) seedlings exposed to Cd. $\mathrm{Cd}(10 \mu \mathrm{M})$ treatment led to significant reductions in plant growth; increases in the levels of superoxide anion radical, hydrogen peroxide, and malondialdehyde; and increases in Cd uptake and accumulation by the roots and shoots in hydroponically grown 10day-old seedlings. Moreover, it reduced AsA content and AsA redox ratios, which have been correlated with reductions in glutathione (GSH) and/or nicotinamide adenine dinucleotide phosphate (NADPH) redox status. However, exogenously applying AsA to Cd-exposed seedlings decreased Cd-induced ROS, improved antioxidant defense systems by increasing AsA, GSH, and NADPH contents, and increased Cd uptake and accumulation in both roots and shoots of the plants. These results provided evidence that the enhancement in AsA redox status can be linked to an increase in the GSH and/or NADPH redox ratios through the induction of the AsA-GSH-NADPH cycle. Thus, these results suggest that exogenous AsA application to oilseed rape seedlings under Cd stress might alleviate the overall Cd toxicity by regulating the homeostasis of the AsA-GSH-NADPH cycle, which reestablishes the steady-state cellular redox status.

Keywords: ascorbate, ascorbate-glutathione-NADPH cycle, cadmium toxicity, oilseed rape, reactive oxygen species

\section{INTRODUCTION}

Cadmium (Cd) pollution is rapidly increasing because of global urbanization and industrialization, whereas the concomitant increase in contaminated farmland and agricultural water supplies has serious effects on the safety of agricultural production. Moreover, because $\mathrm{Cd}$ is highly mobile in soil, it readily contaminates agricultural products through uptake and translocation, even in crops 
cultivated in soil containing low concentrations of Cd. Thus, $\mathrm{Cd}$ is a factor that threatens human health, as humans are high trophic level consumers and may experience $\mathrm{Cd}$ biomagnification (Kim et al., 2008; Hong et al., 2013; Jan et al., 2015; Khan et al., 2015; Jung et al., 2016, 2018b; Farooq et al., 2018).

By weakening the affinity of sulfhydryl groups $(-\mathrm{SH})$ in proteins and disrupting the activity of metabolically important enzymes, $\mathrm{Cd}$ can cause fatal impairments in both plants and humans (Meuwly and Rauser, 1992; Jung et al., 2015, 2016, 2018b). In addition to inhibiting normal plant growth, Cd can replace the cofactors of essential metal ions in important proteins through the Fenton reaction (Peroza et al., 2009 Jung et al., 2015; Jung et al., 2016; Singh et al., 2016; Loix et al., 2017; Jung et al., 2018b). This process generates reactive oxygen species (ROS), such as the superoxide anion radical $\left(\mathrm{O}_{2}{ }^{-}\right)$, hydrogen peroxide $\left(\mathrm{H}_{2} \mathrm{O}_{2}\right)$, hydroxyl radicals $(\mathrm{OH} \cdot)$, and so on. ROS not only destroy cell membranes by intracellular lipid peroxidation but also decrease the biosynthesis of primary metabolites required for plant life, such as carbohydrates, proteins, fats, and nucleic acids, and significantly impair normal vital functions by adversely affecting photosynthesis, respiration, ion absorption, oxidation/reduction, and the homeostatic balance of hormones (Gayomba et al., 2013; Jung et al., 2015, 2016; Singh et al., 2016; Asgari Lajayer et al., 2017). Cd toxicity can be counteracted using various physiological and biochemical detoxification systems to alleviate or minimize oxidative stress caused by excessive absorption and accumulation of Cd (Kim et al., 2008; Srivastava et al., 2014; Singh et al., 2016; Jung et al., 2017, 2018b).

Two antioxidant defense pathways can be used to eliminate the oxidative stress caused by $\mathrm{Cd}$, thereby contributing to maintaining redox homeostasis. The first is an enzymatic antioxidant scavenging pathway using antioxidant or redox enzymes, such as superoxide dismutase (SOD), catalase (CAT), ascorbate peroxidase (APX), monodehydroascorbate reductase (MDHAR), dehydroascorbate reductase (DHAR), and glutathione reductase (GR); the second is a nonenzymatic antioxidant scavenging pathway that uses antioxidant or redox metabolites, including ascorbate (AsA), glutathione (GSH), and nicotinamide adenine dinucleotide phosphate (NADPH) to relieve excessive accumulation of ROS (Gill and Tuteja, 2010; Shekhawat et al., 2010; Foyer and Noctor, 2011; Yan et al., 2015; Sharma et al., 2017).

The roles and functions of antioxidant enzymes and nonenzymatic GSH in scavenging the ROS produced by heavy metals have been thoroughly investigated through numerous studies in various plants (Srivastava et al., 2014; Singh et al., 2015). However, studies on the alleviation of oxidative stress caused by heavy metals through the application of AsA, which plays a critical role in ROS scavenging, redox regulation, plant cell cycle, plant cell growth and development, and damaged DNA restoration, are limited (Akram et al., 2017; Jung et al., 2018a). Akram et al. (2017) comprehensively and systematically demonstrated that AsA plays a very important role in reducing oxidative stress by reviewing the previous reported studies that examined the effect of AsA application on numerous plants subjected to various environmental abiotic stressors including high and low temperature, drought, and salinity. Despite the fact that AsA is used in many different fields to mitigate oxidative stress induced by various environmental stressors (Akram et al., 2017; Chen et al., 2017), there are only a few studies reported on the interaction between Cd toxicity and AsA (Chao et al., 2010; Semida et al., 2018). Chao et al. (2010) reported that hydroponic treatment with AsA reduces malondialdehyde (MDA) production and increases chlorophyll content, thereby contributing to reversing the effects of Cd toxicity in rice. Recently, Semida et al. (2018) reported that sequentially treating seeds with AsA-proline-GSH reduced Cd toxicity in cucumber seedlings and increased plant heavy metal tolerance. Moreover, Jung et al. (2018a) and Zhang et al. (2019) demonstrated the effects of AsA, as a component of the antioxidant-scavenging and redox-regulating system, on reducing arsenic (As) and Cd toxicity in rice and maize plants, respectively.

$\mathrm{Cd}$ contamination not only results in Cd toxicity to plants but also negatively affects the uptake of plant macronutrients (Khan et al., 2015; Jung et al., 2016, 2018b). By inhibiting the absorption of essential macro-elements, Cd causes overall disruption of plant physiological and metabolic activities and impairs normal plant growth and development (Asgari Lajayer et al., 2017). Therefore, understanding and elucidating the effects of AsA on macro-element absorption in plants experiencing $\mathrm{Cd}$ stress will not only provide basic information about its influence on plant macro-element absorption but also inform us regarding its potential to alleviate the antagonistic influences of $\mathrm{Cd}$ on nutrient assimilation.

Oilseed rape (Brassica napus L.) belongs to the family Brassicaceae, which is grown worldwide as an oilseed crop. Plants of Brassicaceae have been used as potential candidates for phytoextraction of heavy metals including $\mathrm{Cd}$ (Gall and Rajakaruna, 2013; Ali et al., 2014; Ahmad et al., 2015). B. napus stands out as a Cd hyperaccumulator owing to its high Cdaccumulating ability, fast plant growth and development, and high biomass in comparison to other natural metal accumulators (Meng et al., 2009; Hasanuzzaman et al., 2017). Nevertheless, AsA-mediated detoxification has not been studied in oilseed rape under Cd stress. Thus, this study was conducted to elucidate the mechanisms whereby $\mathrm{Cd}$ phytotoxicity in oilseed rape may be alleviated. To accomplish this, we evaluated the effects of AsA on Cd uptake, Cd accumulation, ROS production, and redox homeostasis, all of which are related to Cd-induced phytotoxicity, in oilseed rape grown under Cd-contaminated conditions. We also examined the effectiveness of lower-cost foliar (as opposed to soil) AsA treatments to mitigate Cd phytotoxicity in a Cd hyperaccumulator plant (B. napus) that is a candidate for $\mathrm{Cd}$ phytoremediation while also simultaneously examining the mechanisms through which AsA provides Cd resistance. Therefore, the objective of this study was to test the hypothesis that the foliar application of exogenous AsA would be involved in reducing the phytotoxicity caused by the excessive uptake and accumulation of $\mathrm{Cd}$, as well as evaluating the effects on ROS and redox homeostasis, and elucidating whether AsA can be used to remediate Cd-contaminated soil using plants, especially oilseed rape. 


\section{MATERIALS AND METHODS}

\section{Plant Cultivation and Experimental Design}

Oilseed rape (Brassica napus L. cv. Tammi) seeds were surfacesterilized with $70 \%$ ethanol for $3 \mathrm{~min}$ and rinsed extensively with distilled water. The surface-sterilized seeds were germinated under moist conditions (i.e., seeds were covered with two paper towel layers moistened with distilled water) at $25^{\circ} \mathrm{C}$ for $48 \mathrm{~h}$. The germinated seeds were transferred to a hydroponic growth system containing a hydroponic solution. Uniform three-leafstage seedlings were transplanted into plastic pots (two plants per pot) for cultivation. These pots $(30 \mathrm{~cm} \times 25 \mathrm{~cm} \times 15 \mathrm{~cm}$, $0.075-\mathrm{m}^{2}$ surface area) were filled with $9 \mathrm{~L}$ of hydroponic solution containing (mM for the macro-elements): $1.5 \mathrm{NH}_{4} \mathrm{NO}_{3}$, $0.505 \mathrm{KH}_{2} \mathrm{PO}_{4}, 0.045 \mathrm{~K}_{2} \mathrm{HPO}_{4}, 1 \mathrm{~K}_{2} \mathrm{SO}_{4}, 3 \mathrm{CaCl}_{2}, 0.5 \mathrm{MgSO}_{4}$, and $0.4 \mathrm{Fe}$-EDTA and $(\mu \mathrm{M}$ for the micro-elements): 14 $\mathrm{H}_{3} \mathrm{BO}_{3}, 5 \mathrm{MnCl}_{2} \cdot 4 \mathrm{H}_{2} \mathrm{O}, 0.7 \mathrm{CuSO}_{4} \cdot 5 \mathrm{H}_{2} \mathrm{O}, 3 \mathrm{ZnSO}_{4} \cdot 7 \mathrm{H}_{2} \mathrm{O}, 0.7$ $\left(\mathrm{NH}_{4}\right)_{6} \mathrm{Mo}_{7} \mathrm{O}_{24} \cdot 4 \mathrm{H}_{2} \mathrm{O}$, and $0.1 \mathrm{CoCl}_{2} \cdot 6 \mathrm{H}_{2} \mathrm{O}$. The hydroponic solution was $\mathrm{pH}$ adjusted to 5.6, continuously aerated, and replaced every 5 days (Lee et al., 2016). The hydroponically cultivated seedlings were grown in a greenhouse (National Institute of Agricultural Sciences, RDA, Wanju, Jeollabukdo, Korea) with natural sunlight, day/night temperatures of $27^{\circ} \mathrm{C} / 22^{\circ} \mathrm{C}$, and day/night relative humidity of $60 \% / 80 \%$. Plastic pots for each treatment were rearranged daily during the growth and treatment period to minimize environmental variation.

We established five treatments with three replicates per treatment: Cd only, Cd + AsA $\left(250 \mathrm{mg} \mathrm{kg}^{-1}\right), \mathrm{Cd}+\mathrm{AsA}$ $\left(500 \mathrm{mg} \mathrm{kg}{ }^{-1}\right.$ ), AsA only, and an untreated control (no Cd, no AsA); however, we do not present results for the AsA-only treatment as a positive control in this manuscript. According to the previous research results (Chao et al., 2010; Xu et al., 2015; Jung et al., 2018a), the phenotypic responses were not different by AsA-only treatment compared with untreated control treatment. To accomplish this, five-leaf seedlings were grown in hydroponics treated with $10 \mu \mathrm{M} \mathrm{Cd}\left(\mathrm{CdCl}_{2}\right)$ and were simultaneously sprayed with $250 \mathrm{mg} \mathrm{kg}^{-1}(1.42 \mathrm{mM})$ and $500 \mathrm{mg} \mathrm{kg}^{-1}(2.84 \mathrm{mM})$ AsA and $2 \mathrm{ml} \mathrm{L}^{-1}$ commercial surfactant (10\% polyoxyethylene alkyl aryl ether and $20 \%$ sodium lignosulfonate). AsA was applied just once using a handheld sprayer delivering 1,000 $\mathrm{L} \mathrm{ha}^{-1}$ of solution via flat-fan spray tips (Jung et al., 2019). Ten days after treatment, oilseed rape seedlings were removed from pots and tapped with a paper towel to remove water. Then, plant growth characteristics were determined correspondingly. Subsamples $(200 \mathrm{mg}$ ) of roots and leaves were flash-frozen in liquid nitrogen and stored at $-80^{\circ} \mathrm{C}$ until the ROS and redox analyses.

\section{Plant Growth Response}

The effect of AsA application on the plant growth characteristics of oilseed rape seedlings grown in Cd-treated hydroponics with or without the AsA was estimated by determining shoot fresh weight (FW), shoot dry weight (DW), root DW, and shoot water content (WC). After the 10-day treatment period, the seedlings were separated into roots and leaves, and the shoot FW was determined. For shoot WC measurement, the shoots were excised, and their FW was immediately recorded. For shoot DW measurement, the weighed fresh shoots were oven-dried at $60^{\circ} \mathrm{C}$ for $72 \mathrm{~h}$ and then weighed again. Shoot WC in oilseed rape plant was calculated as follows: Shoot WC $(\%)=($ Shoot FW - Shoot DW)/Shoot FW $\times 100$.

\section{Determination of Cadmium and Macro-Mineral Concentrations}

Oilseed rape root and shoot samples were first thoroughly washed with tap water and rinsed extensively with distilled water. Then, the samples were dried at $80^{\circ} \mathrm{C}$ for $72 \mathrm{~h}$ in an oven and subsequently powdered. For determining $\mathrm{Cd}$ and macro-mineral contents in roots and shoots of oilseed rape plants, $200 \mathrm{mg}$ of the powder sample was digested using the Graphite Block Acid Digestion System (ODLAB Co., Ltd., Seoul, Korea). After digestion, the solutions were cooled to ambient temperature, diluted to $100 \mathrm{ml}$ with ultrapure water, and filtered through Grade No. 40 filter papers (Whatman Co., Buckinghamshire, United Kingdom). Cd and macro-mineral contents using this filtrate were determined via inductively coupled plasmamass spectroscopy (ICP-MS) analysis (Agilent 7900; Agilent Technologies Inc., Santa Clara, CA, United States). The following macro-minerals were analyzed: magnesium $(\mathrm{Mg})$, calcium $(\mathrm{Ca})$, iron $(\mathrm{Fe})$, and potassium $(\mathrm{K})$. Cd accumulation in oilseed rape organs was calculated as follows: Cd accumulation $=\mathrm{Ca} \times \mathrm{Cb}$, where $\mathrm{Ca}$ is the $\mathrm{Cd}$ concentration and $\mathrm{Cb}$ is the dry weight in the root and shoot of an oilseed rape plant.

\section{Determination of Superoxide, Hydrogen Peroxide, and Malondialdehyde}

Superoxide anion radical $\left(\mathrm{O}_{2}{ }^{-}\right)$content was determined spectroscopically at $530 \mathrm{~nm}$, following the method developed by Elstner and Heupel (1976); a standard $\mathrm{NaNO}_{2}$ curve was used for calculations. $\mathrm{H}_{2} \mathrm{O}_{2}$. content was measured colorimetrically according to the method described by Jana and Choudhuri (1982). Sample absorbance was measured at $410 \mathrm{~nm}$, and $\mathrm{H}_{2} \mathrm{O}_{2}$ content was calculated using an extinction coefficient of $0.28 \mu^{-1} \mathrm{~cm}^{-1}$. Lipid peroxidation was indirectly estimated using the level of MDA by the thiobarbituric acid method of Buege and Aust (1978) with slight modifications. Sample absorbance was measured at $532 \mathrm{~nm}$ and corrected for nonspecific turbidity by subtracting the value from the absorbance at $600 \mathrm{~nm}$. MDA content was calculated using an extinction coefficient of $156 \mathrm{mM}^{-1} \mathrm{~cm}^{-1}$.

\section{Determination of AsA/DHA, GSH/GSSG, and NADPH/NADP+}

The total AsA, reduced AsA, and oxidized dehydroascorbate (DHA) contents were assayed colorimetrically according to the method described by Law et al. (1983). The absorbance of samples was calculated at $525 \mathrm{~nm}$, and the total and reduced AsA contents were calculated using a standard AsA curve. The DHA content was recalculated by subtracting the reduced AsA content from the total AsA content.

The reduced GSH and oxidized GSSG contents were assayed according to the method described by 
Meister and Anderson (1983). The absorbance of samples was calculated at $412 \mathrm{~nm}$ for $1 \mathrm{~min}$, and total GSH and oxidized GSSG contents were determined using linear regression obtained from a standard curve of GSH and GSSG. The reduced GSH content was recalculated by subtracting the oxidized GSSG content from the total GSH content.

The reduced NADPH and oxidized $\mathrm{NADP}^{+}$contents were assayed following the method of Queval and Noctor (2007). For the NADPH and $\mathrm{NADP}^{+}$extraction, frozen root and leaf organs were ground in liquid nitrogen and then resuspended with either $0.8 \mathrm{ml}$ of $0.2 \mathrm{M} \mathrm{HCl}$ or $0.2 \mathrm{M} \mathrm{NaOH}$, respectively. One hundred microliters per extract was heated at $95^{\circ} \mathrm{C}$ for $1 \mathrm{~min}$ and stopped in an ice bath. The supernatant was neutralized by $0.2 \mathrm{M} \mathrm{HCl}$ to a final $\mathrm{pH}$ of $7-8$ for the NADPH assay and counteracted by $0.2 \mathrm{M} \mathrm{NaOH}$ to a final $\mathrm{pH}$ of $5-6$ for the $\mathrm{NADP}^{+}$assay. Forty microliters were added to each reaction mixture containing $0.1 \mathrm{M}$ HEPES ( $\mathrm{pH} 7.5$ ) that consisted of $2 \mathrm{mM} \mathrm{Na}{ }_{2}$ EDTA, $1.2 \mathrm{mM}$ dichlorophenolindophenol (DCPIP), $20 \mathrm{mM}$ phenazine methosulfate (PMS), and $10 \mathrm{mM}$ glucose6-phosphate. The reaction started by adding $2 \mu$ glucose 6phosphate dehydrogenase $(\mathrm{G} 6 \mathrm{PDH}, 200 \mathrm{U})$. The NADPH and $\mathrm{NADP}^{+}$contents were determined using a standard curve with standards of 1-100 pmol.

\section{Determination of Antioxidant Enzyme Activities}

The antioxidant enzymes were extracted with $100 \mathrm{mM}$ potassium phosphate buffer $(\mathrm{pH} 7.5)$ containing $2 \mathrm{mM}$ of ethylenediaminetetraacetic acid (EDTA), 1\% polyvinyl pyrrolidone-40 (PVP-40), and $1 \mathrm{mM}$ of phenylmethylsulfonyl fluoride (PMSF), as described by Lee et al. (2013). After enzyme extraction of samples, the protein concentration was determined using the detailed method of Kruger (1994).

SOD (EC 1.15.1.1) activity was assayed according to Lee et al. (2009) by measuring the enzyme ability to inhibit the photoreduction of nitroblue tetrazolium (NBT). One unit of SOD activity was defined as the amount of enzyme that inhibited the rate of NBT photoreduction by $50 \%$ at $560 \mathrm{~nm}$. SOD activity indicated units of SOD $\mathrm{mg}^{-1}$ protein.

CAT (EC 1.11.1.6) activity was determined based on the method of Lee et al. (2013) by monitoring the decrease in absorbance at $240 \mathrm{~nm}$ for 1 min (extinct coefficient, $\varepsilon=36 \mathrm{mM}^{-1} \mathrm{~cm}^{-1}$ ) as a result of $\mathrm{H}_{2} \mathrm{O}_{2}$ degradation. CAT activity indicated $\mu \mathrm{mol} \mathrm{H}_{2} \mathrm{O}_{2}$ decomposed $\mathrm{min}^{-1} \mathrm{mg}^{-1}$ protein.

APX (EC 1.11.1.11) activity was measured according to the method of Chen and Asada (1989) by monitoring the decline in absorbance at $290 \mathrm{~nm}$ for $1 \mathrm{~min}$ (extinct coefficient, $\varepsilon=2.8 \mathrm{mM}^{-1} \mathrm{~cm}^{-1}$ ) as AsA was oxidized. APX activity indicated $\mu$ mol ascorbate $\mathrm{min}^{-1} \mathrm{mg}^{-1}$ protein.

MDHAR (EC 1.6.5.4) activity was evaluated using the method described by Hossain et al. (1984) by monitoring the decrease in absorbance at $340 \mathrm{~nm}$ for $1 \mathrm{~min}\left(6.2 \mathrm{mM}^{-1} \mathrm{~cm}^{-1}\right)$ as NADPH was oxidized. MDHAR activity indicated nmol NADH $\mathrm{min}^{-1} \mathrm{mg}^{-1}$ protein.

DHAR (EC 2.5.1.1.8) activity was measured colorimetrically according to the method described by Nakano and Asada (1981) by monitoring the increase in absorbance at $265 \mathrm{~nm}$ for $1 \mathrm{~min}$ $\left(14 \mathrm{mM}^{-1} \mathrm{~cm}^{-1}\right)$ as DHA was reduced. DHAR activity indicated nmol ascorbate $\mathrm{min}^{-1} \mathrm{mg}^{-1}$ protein.

GR (EC 1.6.4.2) activity was assayed according to the method of Rao et al. (1996) by monitoring the decrease in absorbance at $340 \mathrm{~nm}$ for $1 \mathrm{~min}$ (extinct coefficient, $\varepsilon=6.2 \mathrm{mM}^{-1} \mathrm{~cm}^{-1}$ ) as NADPH was oxidized. GR activity indicated $\mu \mathrm{mol}$ NADPH $\mathrm{min}^{-1} \mathrm{mg}^{-1}$ protein.

\section{Statistical Analysis}

Analysis of variance (ANOVA) was applied to all data, and Fisher's least significant difference (LSD) test was used to determine significant differences among treatments. All statistical analyses were performed using statistical analysis software (SAS ver. 9.2; SAS Institute Inc., Cary, NC, United States). Differences at $P<0.05$ were considered significant. In the figures, the data are expressed as mean \pm standard deviation (SD).

To elucidate the response of targeted metabolites of ROS and AsA/GSH/NADPH redox status in the roots and leaves of oilseed rape plants treated with different levels of AsA, correlation coefficient analysis and principal component analysis (PCA) were performed using MetaboAnalyst $4.0^{1}$ (Chong et al., 2018) for heatmap generation and cluster analysis, respectively.

\section{RESULTS}

\section{Changes in the Plant Growth Characteristics in Cadmium-Stressed Oilseed Rape Seedlings With or Without Ascorbate Application}

Shoot FW and DW of the Cd-only-treated seedlings were significantly decreased by $\mathrm{Cd}$ treatment compared with those of the untreated plants. However, Cd treatment had no effect on the root DW and shoot WC. Moreover, plant growth characteristics were not significantly different in the untreated seedlings than in the seedlings treated with AsA alone (data not shown). Notably, exogenous applications of AsA to Cd-exposed seedlings significantly alleviated the negative influences of $\mathrm{Cd}$ on the shoot FW and DW of these plants (Table 1).

\section{Changes in the Cadmium Uptake and Accumulation in Cadmium-Stressed Oilseed Rape Seedlings With or Without Ascorbate Application}

In the oilseed rape seedlings treated with $\mathrm{Cd}$ alone, the $\mathrm{Cd}$ content was significantly higher in the roots than that in the shoots. Application of 250 and $500 \mathrm{mg} \mathrm{kg}^{-1}$ AsA in Cd-treated plants enhanced Cd uptake and accumulation. AsA treatment induced approximately 1.57 - and 1.11-fold increases in Cd uptake in the roots and shoots, respectively, relative to Cd uptake in roots and shoots of plants treated with $\mathrm{Cd}$ alone (Figure 1A). Although the evaluation of $\mathrm{Cd}$ accumulation in the roots and shoots was

\footnotetext{
${ }^{1}$ www.metaboanalyst.ca
} 
TABLE 1 | Effect of ascorbate (AsA) application on plant growth characteristics of oilseed rape seedlings grown in cadmium (Cd)-treated hydroponics.

\begin{tabular}{|c|c|c|c|c|}
\hline Treatment & Shoot FW (g) & Shoot DW (g) & Root DW (g) & Shoot WC (\%) \\
\hline Control & $64.5 \pm 0.9 a$ & $4.73 \pm 0.20 \mathrm{a}$ & $0.33 \pm 0.03 a$ & $92.7 \pm 0.4 \mathrm{a}$ \\
\hline $10 \mu \mathrm{M} \mathrm{Cd}+0 \mathrm{mg} \mathrm{AsA} \mathrm{kg}{ }^{-1}$ & $54.7 \pm 2.2 b$ & $3.91 \pm 0.18 b$ & $0.30 \pm 0.05 a$ & $92.6 \pm 0.7 \mathrm{a}$ \\
\hline $10 \mu \mathrm{M} \mathrm{Cd}+250 \mathrm{mg} \mathrm{AsA} \mathrm{kg}{ }^{-1}$ & $62.8 \pm 0.8 \mathrm{a}$ & $4.60 \pm 0.03 a$ & $0.32 \pm 0.02 \mathrm{a}$ & $92.8 \pm 0.2 \mathrm{a}$ \\
\hline $10 \mu \mathrm{M} \mathrm{Cd}+500 \mathrm{mg} \mathrm{AsA} \mathrm{kg}{ }^{-1}$ & $64.7 \pm 3.8 \mathrm{a}$ & $4.70 \pm 0.06 \mathrm{a}$ & $0.33 \pm 0.02 \mathrm{a}$ & $92.6 \pm 0.4 \mathrm{a}$ \\
\hline
\end{tabular}

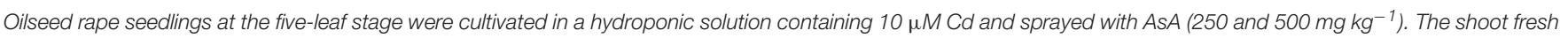
weight (FW), shoot dry weight (DW), root DW, and shoot water content (WC) were measured at 10 days after treatment.

${ }^{\dagger}$ Means within a column followed by the same letter are not significantly different at the $P<0.05$ level based on Fisher's least significant difference (LSD) tests.

based on the biomass (root and shoot DW per plant), trends for Cd accumulation were similar to those for Cd uptake. The Cd accumulation was 1.72- and 1.70-fold higher in the roots and 1.31- and 1.51-fold higher in the shoots in the 250 and $500 \mathrm{mg} \mathrm{kg}^{-1}$ AsA treatments, respectively, than that in the Cd-only treatment (Figure 1B).
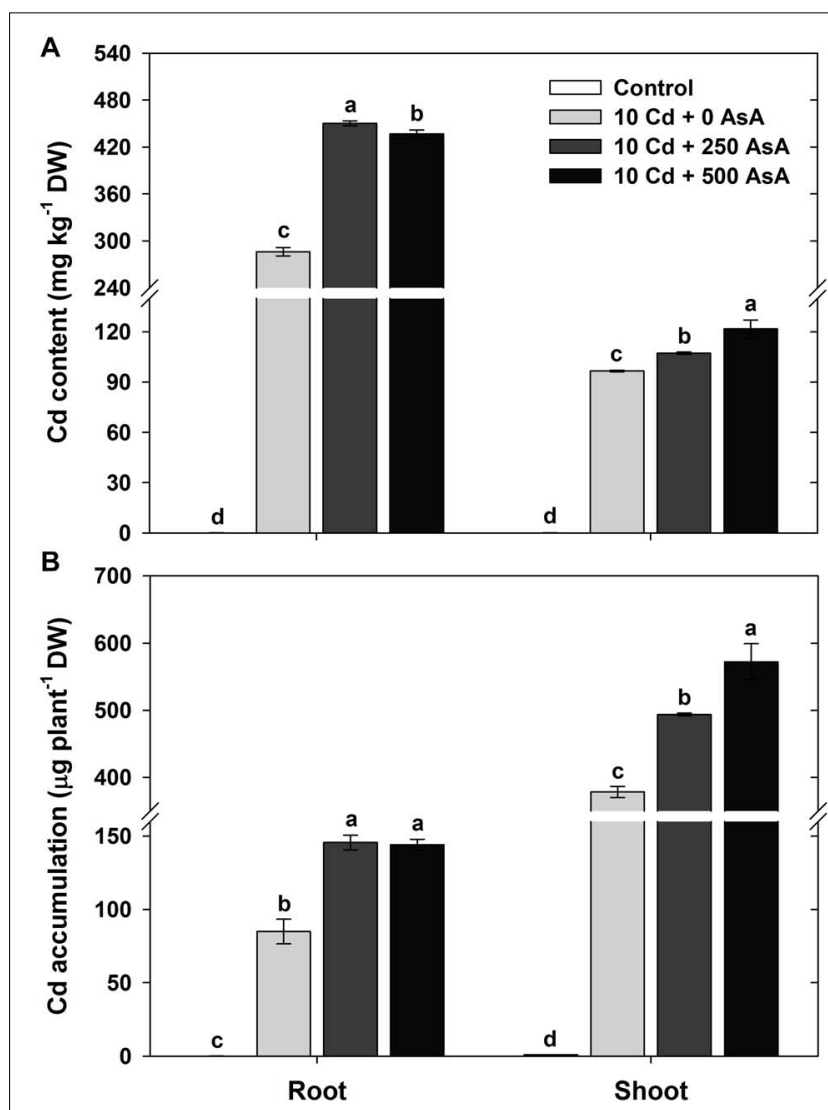

FIGURE 1 | Effect of ascorbate (AsA) application on the cadmium (Cd) content (A) and $\mathrm{Cd}$ accumulation (B) of the root and shoot of oilseed rape seedlings grown in Cd-treated hydroponics. Oilseed rape seedlings at the five-leaf stage were cultivated in a hydroponic solution containing $10 \mu \mathrm{M} \mathrm{Cd}$ and sprayed with AsA (250 and $500 \mathrm{mg} \mathrm{kg}^{-1}$ ). Ten days after treatment, the level of $\mathrm{Cd}$ in the roots and shoots was measured via inductively coupled plasma-mass spectroscopy analysis. The data are presented as mean \pm standard deviation (SD) of the mean of three replications $(n=3)$. Means denoted by the same letter are not significantly different at the $P<0.05$ level according to Fisher's least significant difference (LSD) test.

\section{Changes in the Macro-Mineral Uptake in Cadmium-Stressed Oilseed Rape Seedlings With or Without Ascorbate Application}

The macro-minerals $\mathrm{Mg}, \mathrm{Ca}, \mathrm{Fe}$, and $\mathrm{K}$ were measured in the roots and shoots to evaluate the effect of AsA in the Cd-stressed seedlings on nutrient acquisition. Compared with that of the untreated plants, Cd treatment did not inhibit $\mathrm{Mg}, \mathrm{Ca}$, and $\mathrm{K}$ uptake in the roots and shoots (Figures 2A,B,D). However, the Fe content in both plant organs was significantly reduced by $\mathrm{Cd}$ treatment (Figure 2C). Notably, the plants subjected to AsA treatments exhibited significantly higher contents of $\mathrm{Mg}, \mathrm{Ca}$, and $\mathrm{Fe}$ in the roots and shoots than those treated with $\mathrm{Cd}$ alone (Figures 2A-C).

\section{Reactive Oxygen Species Production in Cadmium-Stressed Oilseed Rape Seedlings With or Without Ascorbate Application}

To quantify the oxidative responses of oilseed rape seedling to $\mathrm{Cd}$ toxicity, we determined the $\mathrm{O}_{2}{ }^{-}$(Figure 3A), $\mathrm{H}_{2} \mathrm{O}_{2}$ (Figure 3B), and MDA (Figure 3C) contents in plants at 10 days after AsA application and $\mathrm{Cd}$ treatment. First, we note that ROS production in oilseed rape seedlings that were treated only with AsA (no addition of $\mathrm{Cd}$ ) was not significantly different from ROS production in the untreated control plants (data not shown).

Cd stress increased ROS production in B. napus seedlings. The contents of each of these compounds in both organs were significantly higher in Cd-exposed plants than those in untreated seedlings. Oilseed rape plants grown in the Cd-treated hydroponics showed severe symptoms of $\mathrm{Cd}$ toxicity, such as plant growth inhibition, compared with those of the untreated control (Table 1).

However, exogenous applications of 250 and $500 \mathrm{mg} \mathrm{kg}^{-1}$ AsA to Cd-treated seedlings significantly reduced $\mathrm{O}_{2} \cdot-$ and $\mathrm{H}_{2} \mathrm{O}_{2}$ content compared to that of the plants treated with $\mathrm{Cd}$ alone; thus, AsA application rescued seedlings from the increased ROS production induced by $\mathrm{Cd}$ toxicity (Figures 3A,B). In addition, AsA application significantly decreased the MDA content produced by $\mathrm{Cd}$ toxicity in both organs (Figure 3C). 

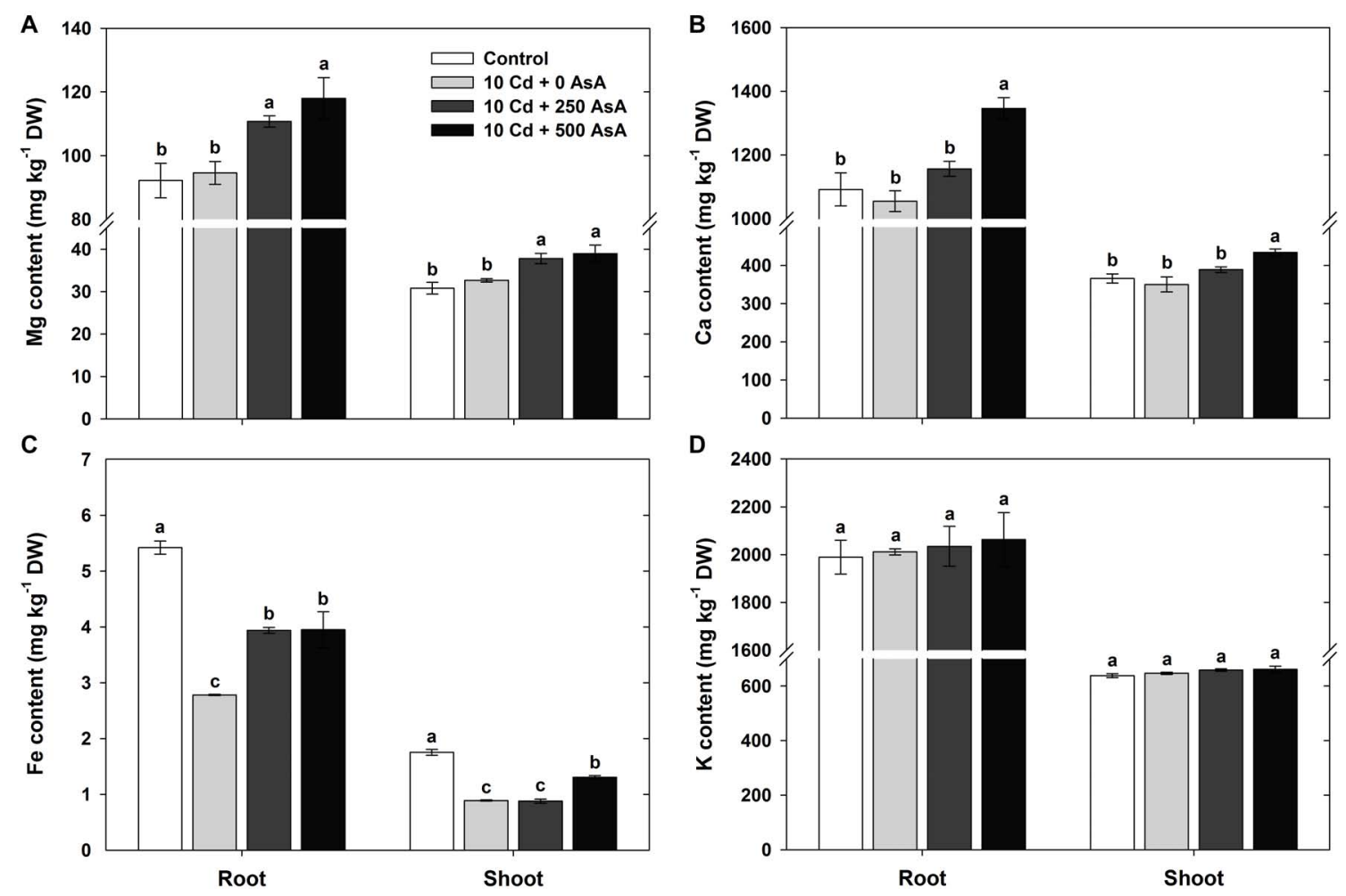

FIGURE 2 | Effect of ascorbate (AsA) application on the magnesium (Mg) (A), calcium (Ca) (B), iron (Fe) (C), and potassium (K) (D) contents of the root and shoot of oilseed rape seedlings grown in cadmium (Cd)-treated hydroponics. Oilseed rape seedlings at the five-leaf stage were cultivated in a hydroponic solution containing $10 \mu \mathrm{M} \mathrm{Cd}$ and sprayed with AsA (250 and $500 \mathrm{mg} \mathrm{kg}^{-1}$ ). Ten days after treatment, the level of each cation in the roots and shoots was measured via inductively coupled plasma-mass spectroscopy analysis. The data are presented as mean \pm standard deviation (SD) of the mean of three replications ( $n=3$ ). Means denoted by the same letter are not significantly different at the $P<0.05$ level according to Fisher's least significant difference (LSD) test.

\section{Redox Status in Cadmium-Stressed Oilseed Rape Seedlings}

When plants are exposed to Cd stress, the alteration of the cellular redox conditions could be closely associated not only with the AsA redox ratio (AsA/DHA) and the GSH redox ratio (GSH/GSSG), but also with the NADPH redox ratio $\left(\mathrm{NADPH} / \mathrm{NADP}^{+}\right)$. To understand the effect of $\mathrm{Cd}$ stress on plant redox status, the AsA, GSH, and NADPH levels and redox status in roots and leaves were evaluated at 10 days after plants had either received $\mathrm{Cd}$ or no treatment. All comparisons below are between Cd-treated (no AsA) seedlings and the untreated control seedlings.

Cd toxicity increased both the DHA level and the AsA redox status in B. napus seedlings, but it had differential plant organ-specific effects on AsA levels. In Cd-stressed seedlings, the AsA level in roots was not significantly different from that of the untreated control seedlings, but leaf AsA levels declined significantly (Figure 4A). However, the DHA level, the oxidized form of AsA, was significantly higher in both roots (1.37-fold increase) and leaves (1.26fold increase) of plants exposed to Cd (Figure 4D). Cd treatment reduced AsA redox status in both roots $(-28 \%)$ and leaves $(-42 \%)$ compared to those of the untreated control plants (Figure 4G).
Cd toxicity increased GSSG but reduced GSH and the GSH redox status in B. napus seedlings. The GSH level in the roots and leaves of Cd-treated plants was 67 and $82 \%$ lower than that of the untreated plants, respectively (Figure 4B). However, the level of GSSG, the oxidized form of GSH, in roots and leaves was 290 and $184 \%$ higher in the Cd-stressed seedlings than that in the untreated seedlings, respectively (Figure 4E). The GSH redox status in the Cd-stressed seedlings greatly decreased by $88 \%$ in the roots and by $90 \%$ in the leaves compared to those of the untreated control plants (Figure $4 \mathrm{H}$ ).

Finally, Cd toxicity increased NADPH, reduced NADPH redox ratios, and had no effect on $\mathrm{NADP}^{+}$levels in B. napus seedlings. The NADPH contents of Cd-treated seedling roots and leaves were not statistically different from those of the untreated controls (Figure 4C). In contrast, the content of $\mathrm{NADP}^{+}$, the oxidized form of NADPH, largely increased in the roots and leaves under Cd stress (Figure 4F). NADPH redox ratios were significantly lower in the roots and leaves of the Cd-stressed plants than those in the untreated plants (Figure 4I).

\section{Redox Status in Cadmium-Stressed Oilseed Rape Treated With Ascorbate}

In addition to examining the effects of $\mathrm{Cd}$ stress on seedling redox status, we also examined the effects of applying AsA to plants 

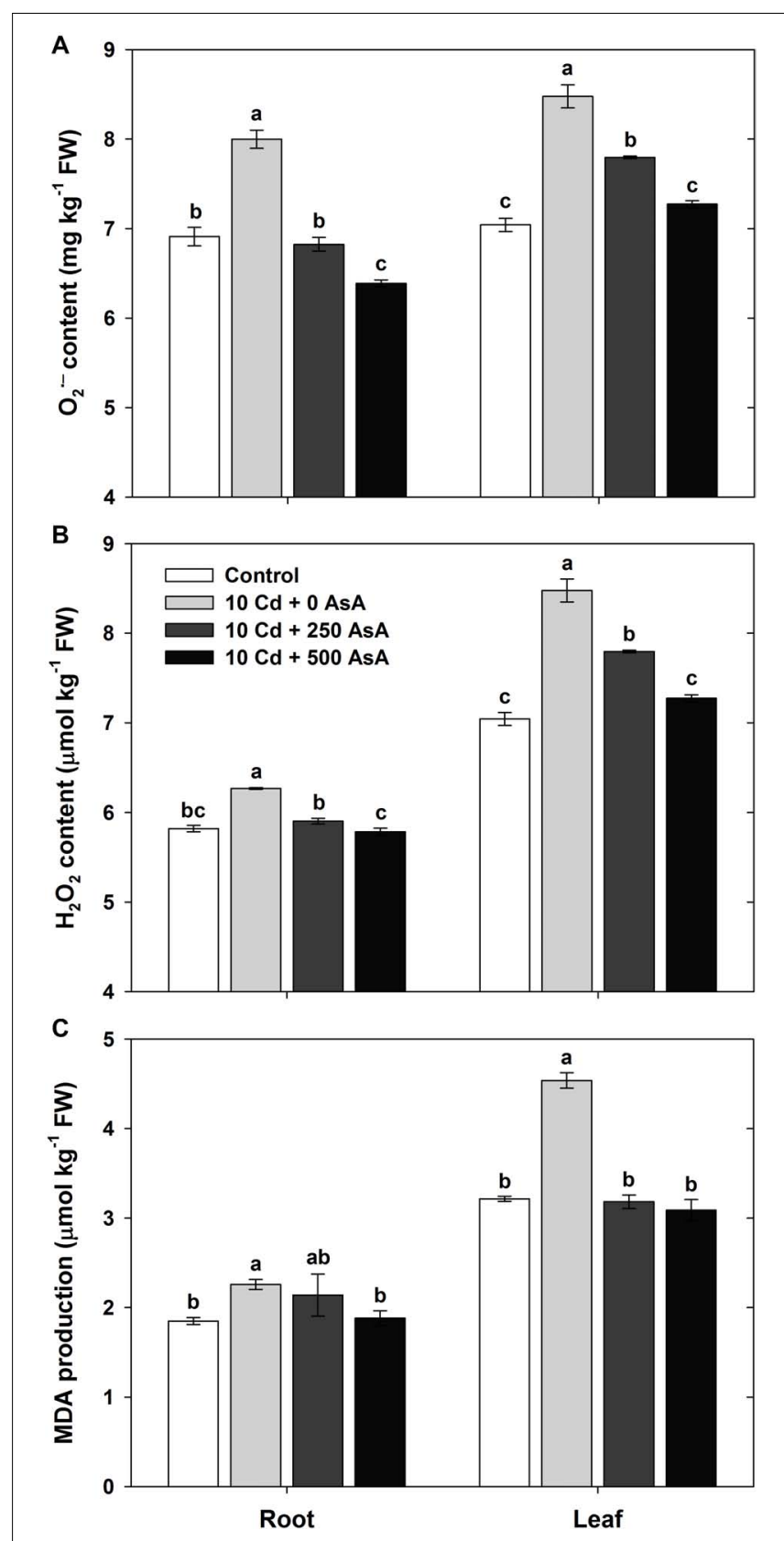

FIGURE 3 | Effect of ascorbate (AsA) application on the contents of superoxide $\left[(\mathbf{A}) \mathrm{O}_{2}{ }^{-}\right)$] and hydrogen peroxide $\left[(\mathbf{B}) ; \mathrm{H}_{2} \mathrm{O}_{2}\right]$ and malondialdehyde (MDA) production [(C) MDA] of oilseed rape seedlings grown in cadmium (Cd)-treated hydroponics. Oilseed rape seedlings at the five-leaf stage were cultivated in a hydroponic solution containing $10 \mu \mathrm{M} \mathrm{Cd}$ and sprayed with AsA (250 and $500 \mathrm{mg} \mathrm{kg}^{-1}$ ). Ten days after treatment, the contents of $\mathrm{O}_{2} \cdot{ }^{-}, \mathrm{H}_{2} \mathrm{O}_{2}$, and MDA in the roots and leaves were measured. The data are presented as mean \pm standard deviation (SD) of the mean of three replications $(n=3)$. Means denoted by the same letter are not significantly different at the $P<0.05$ level according to Fisher's least significant difference (LSD) test.

experiencing $\mathrm{Cd}$ stress and compared them with plants treated with $\mathrm{Cd}$. To evaluate the potential of AsA to ameliorate the effects of Cd stress on seedling redox status, the AsA, GSH, and NADPH levels and redox status in roots and leaves were evaluated at 10 days posttreatment with $\mathrm{Cd}$ and/or AsA. All comparisons below are between seedlings receiving $\mathrm{Cd}+\mathrm{AsA}$ and seedlings receiving only $\mathrm{Cd}$. Moreover, two levels of AsA application were evaluated: 250 and AsA $500 \mathrm{mg} \mathrm{kg}^{-1}$.

Applying AsA to Cd-stressed plants increased their AsA content across both seedling plant organ types (i.e., leaves and roots) and AsA treatment levels (i.e., 250 and $500 \mathrm{mg} \mathrm{kg}^{-1}$ ), but the effects of AsA application on DHA and AsA redox ratios varied depending on the plant organ type and the amount of AsA applied. The AsA content increased in the roots and leaves of AsA-treated plants (Cd + AsA) compared to that of Cd-onlytreated plants (Figure 4A). On the other hand, root DHA content did not change with the application of $250 \mathrm{mg} \mathrm{kg}^{-1}$ AsA and slightly increased in response to $500 \mathrm{mg} \mathrm{kg}^{-1}$ AsA, but leaf DHA significantly decreased in both AsA treatments (Figure 4D). The AsA redox ratio in roots was not significantly different at either level of AsA treatment from that in the Cd-only treatment (Figure 4G). However, a high AsA redox ratio was maintained in the leaves because AsA application had both increased the AsA content and decreased the DHA content relative to the Cd-only-treated plants (Figure 4G).

AsA application dramatically increased GSH, while having a neutral to negative effect on GSSG, thereby contributing to increasing the GSH ratio in B. napus seedlings experiencing $\mathrm{Cd}$ stress. The 250 and $500 \mathrm{mg} \mathrm{kg}^{-1}$ AsA applications increased GSH 3.62- and 3.16-fold in plant roots and 6.16- and 5.99fold in plant leaves, respectively, compared to GSH levels in the Cd-only-treated seedlings (Figure 4B). The GSSG level in the $250 \mathrm{mg} \mathrm{kg}^{-1}$ AsA-treated seedlings significantly decreased in both plant organs, but the root and leaf GSSG levels in the $500 \mathrm{mg} \mathrm{kg}^{-1}$ AsA-treated plants were not significantly different from those of the Cd-only treatment (Figure 4E). AsA treatment significantly increased the GSH redox ratio in both the roots and leaves of Cd-stressed plants (Figure 4H).

Finally, AsA application increased NADPH but had a dosedependent neutral-to-positive effect on $\mathrm{NADP}^{+}$, resulting in neutral (in leaves) to positive (in roots) effects on the NADPH redox ratio. The NADPH levels in the roots and leaves of the 250 and $500 \mathrm{mg} \mathrm{kg}^{-1}$ AsA-treated plants greatly increased compared to those of the Cd-only-treated plants (Figure 4C). The NADP ${ }^{+}$ level was not significantly altered in either plant organ in the $250 \mathrm{mg} \mathrm{kg}{ }^{-1}$ AsA-treated plants, but it increased in roots and leaves of the $500 \mathrm{mg} \mathrm{kg}^{-1}$ AsA-treated plants (Figure 4F). Exogenous AsA treatments significantly increased the NADPH redox ratio in the roots, while not significantly changing it in the leaves (Figure 4I).

\section{Changes in the Antioxidant Scavenging Enzymes in Cadmium-Stressed Oilseed Rape Seedlings With or Without Ascorbate Application}

With an increase in the amount of AsA applied to Cd-stressed plants, there was a concomitant decrease in the observed amount of Cd-induced ROS (Figure 3). Based on the ROS responses, SOD, CAT, APX, MDHAR, DHAR, and GR activities were 

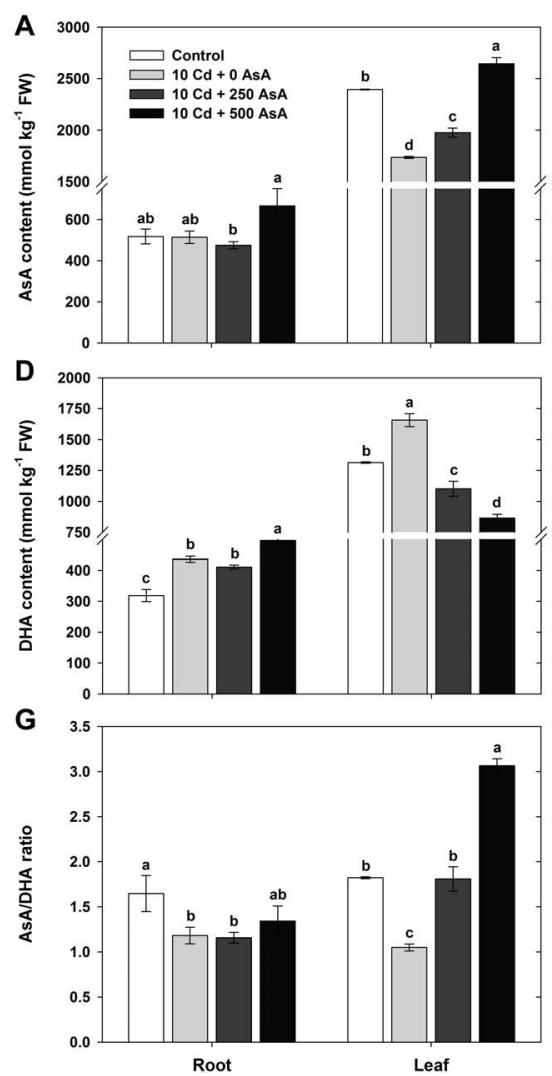
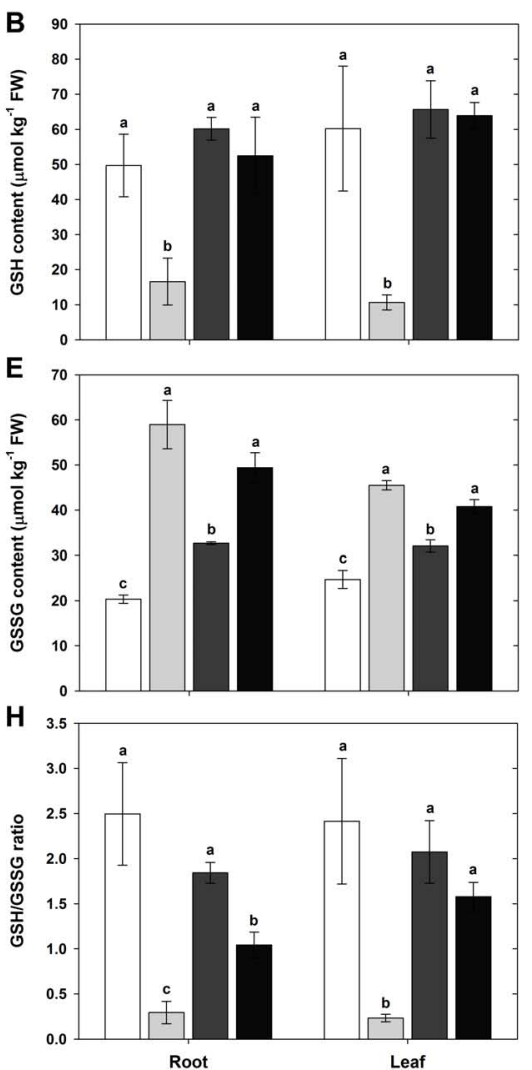
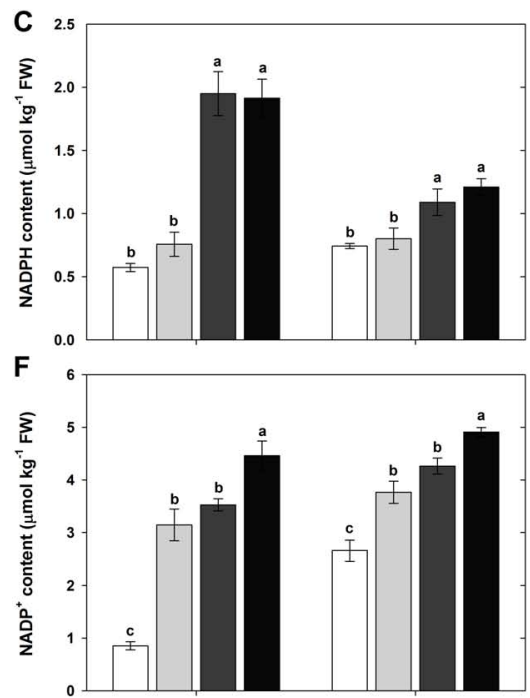

I

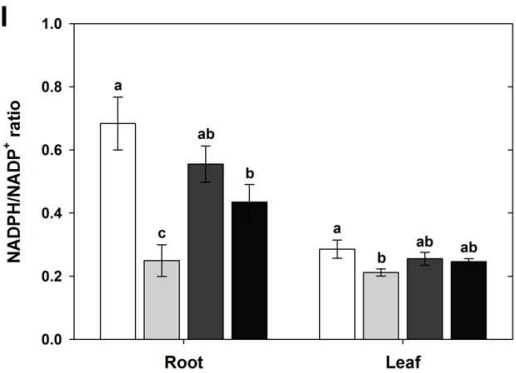

FIGURE 4 | Effect of ascorbate (AsA) application on the contents of AsA (reduced form)/glutathione (GSH, reduced form)/nicotinamide adenine dinucleotide phosphate (NADPH, reduced form) and dehydroascorbate (DHA, oxidized form)/GSH disulfide (GSSG, oxidized form)/nicotinamide adenine dinucleotide phosphate (NADP ${ }^{+}$, oxidized form) and the AsA/GSH/NADPH redox ratio in oilseed rape seedlings grown in the cadmium (Cd)-treated hydroponics. Oilseed rape seedlings at the five-leaf stage were cultivated in a hydroponic solution containing $10 \mu \mathrm{M} \mathrm{Cd}$ and sprayed with AsA (250 and $\left.500 \mathrm{mg} \mathrm{kg}^{-1}\right)$. Ten days after treatment, the levels of AsA/GSH/NADPH and DHA/GSSG/NADP ${ }^{+}$and the AsA/GSH/NADPH redox ratio in the roots and leaves were measured. (A-C) Content of AsA, GSH, and NADPH. (D-F) Contents of DHA, GSSG, and NADP ${ }^{+}$. (G-I) AsA, GSH, and NADPH redox ratios (AsADHA, GSH/GSSG, and NADPH/NADP+). The data are presented as mean \pm standard deviation $(\mathrm{SD})$ of the mean of three replications $(n=3)$. Means denoted by the same letter are not significantly different at the $P<0.05$ level according to Fisher's least significant difference (LSD) test.

measured in the roots and leaves to investigate the influence of AsA on the antioxidant scavenging system in Cd-exposed plants. SOD, CAT, and APX activities in the plants treated with Cd alone increased 1. 22-, 5. 00-, and 1.41-fold in the roots and 1. 16-, 1 . 31-, and 1.51-fold in the leaves compared to those of the untreated plants, respectively (Figures 5A-C). However, MDHAR, DHAR, and GR activities were significantly lower in both the roots and leaves under Cd stress (Figures 5D,E).

The Cd-stressed seedlings supplied with either 250 or $500 \mathrm{mg} \mathrm{kg}^{-1}$ AsA had significantly lower SOD activity in all organs than that of the seedlings treated with $\mathrm{Cd}$ but without AsA (Figure 5A). CAT activity in the roots was decreased by AsA treatment, while no change in CAT activity was observed in the leaves, compared to that of the Cd-only-treated plants (Figure 5B). APX activity decreased in the leaves, but was not significantly altered in the roots, compared to that of the Cd-only-treated plants (Figure 5C). The seedlings treated with $\mathrm{Cd}+$ AsA had increased MDHAR activity in the roots, but MDHAR markedly decreased ( $-43 \%$ at $250 \mathrm{mg} \mathrm{kg}^{-1} \mathrm{AsA},-39 \%$ at $500 \mathrm{mg} \mathrm{kg}^{-1} \mathrm{AsA}$ ) in the leaves compared to those of the
Cd-treated plants (Figure 5D). Although the Cd alone treatment showed decreases in the DHAR and GR activities, treatment with AsA in the Cd-exposed seedlings resulted in significant increases in these activities in both the roots and leaves compared to those of the Cd alone treatment (Figures 5E,F).

\section{Heatmap Responses of the Targeted Metabolites of Reactive Oxygen Species and AsA/GSH/NADPH Redox From Cadmium-Stressed Oilseed Rape Seedlings With or Without Ascorbate Application}

A normalized heatmap matrix system was used to elucidate the overall responses of oilseed rape seedlings to AsA treatment under $\mathrm{Cd}$ stress conditions. The results of a normalized heatmap matrix indicated that the treatments elicited differential responses between roots and shoots. In addition, the cluster responses for the Cd-only treatment were the least clustered with the other three treatments irrespective of organ type. 

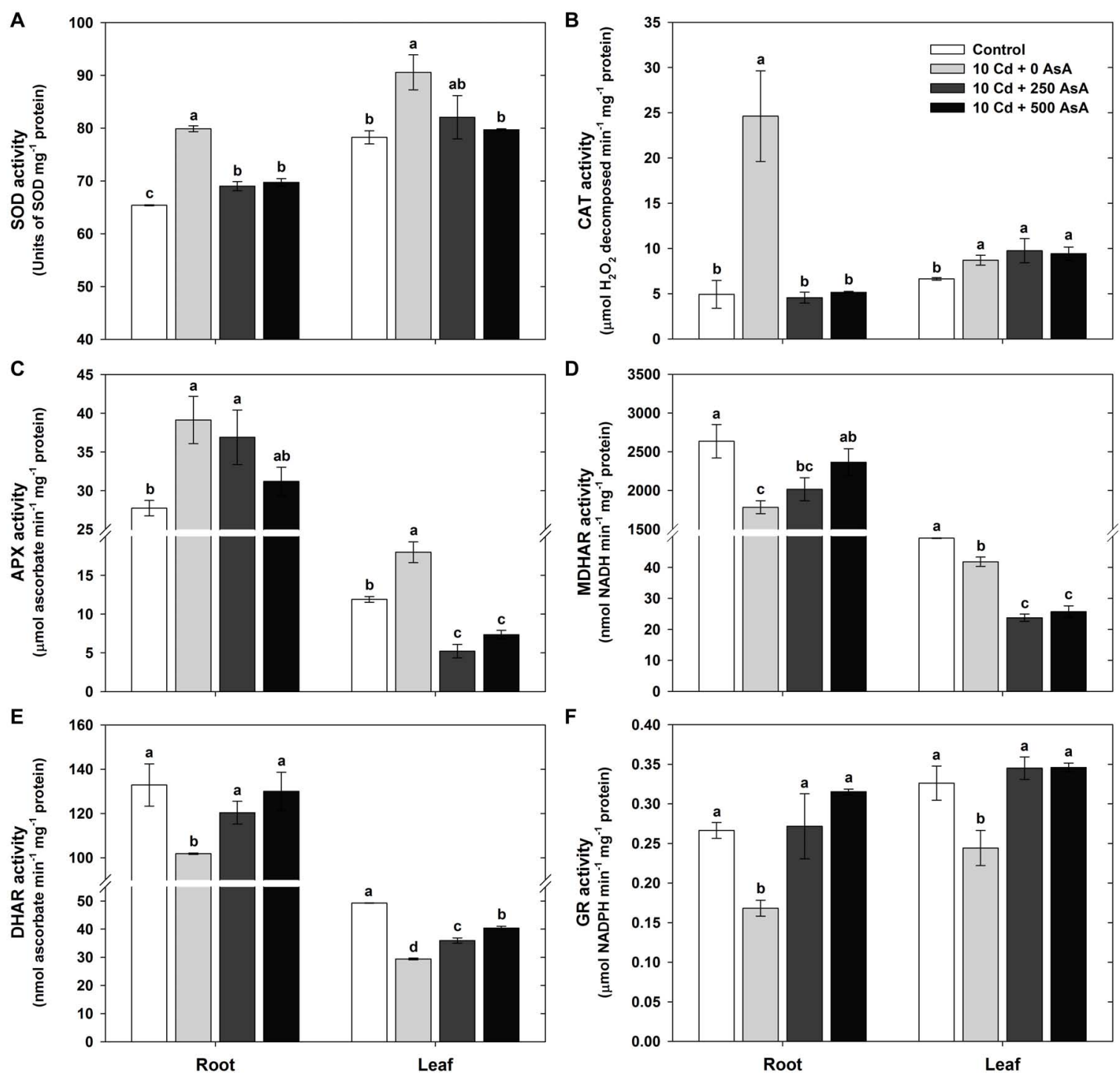

FIGURE 5 | Effect of ascorbate (AsA) application on the activities of antioxidant enzymes of oilseed rape seedlings grown in cadmium (Cd)-treated hydroponics; superoxide dismutase [(A) SOD], catalase [(B) CAT], ascorbate peroxidase [(C) APX], monodehydroascorbate reductase [(D) MDHAR], dehydroascorbate reductase [(E) DHAR], and glutathione reductase [(F) GR] activities. Oilseed rape seedlings at the five-leaf stage were cultivated in a hydroponic solution containing $10 \mu \mathrm{M}$ Cd and sprayed with AsA (250 and $500 \mathrm{mg} \mathrm{kg}^{-1}$ ). Ten days after treatment, the activity of each antioxidant enzymes in the roots and leaves was measured. The data are presented as mean \pm standard deviation (SD) of the mean of three replications $(n=3)$. Means denoted by the same letter are not significantly different at the $P<0.05$ level according to Fisher's least significant difference (LSD) test.

That is, AsA treatments were closely clustered with the untreated control in both leaves and roots. Furthermore, the normalized heatmap indicates that, regardless of AsA treatment under $\mathrm{Cd}$ stress conditions, plant organs exhibited differential responses across the response variables examined (Figure 6). The normalized responses of GSH, GSH/GSSG ratio, MDA, DHA, ROS, SOD, Cd accumulation, $\mathrm{NADP}^{+}$, AsA/DHA ratio, GR, DW, and AsA were relatively higher in shoots than roots. In contrast, $\mathrm{NADPH} / \mathrm{NADP}^{+}$ratio, APX, K, Mg, Ca, Fe, MDHAR, DHAR, Cd, and NADPH had relatively higher normalized responses in roots than in shoots (Figure 6).

\section{Principal Component Analysis of the Targeted Metabolites of Reactive Oxygen Species and AsA/GSH/NADPH Redox From Cadmium-Stressed Oilseed Rape Seedlings With or Without Ascorbate Application}

A PCA scores plot was applied to evaluate the overall responses of oilseed rape seedlings to AsA treatment under Cd stress conditions. The results of the PCA scores plot accounted for 60.6 and $16.3 \%$ of the total variance of principal components (PC) 1 and 2, respectively, and indicated that organ responses to 


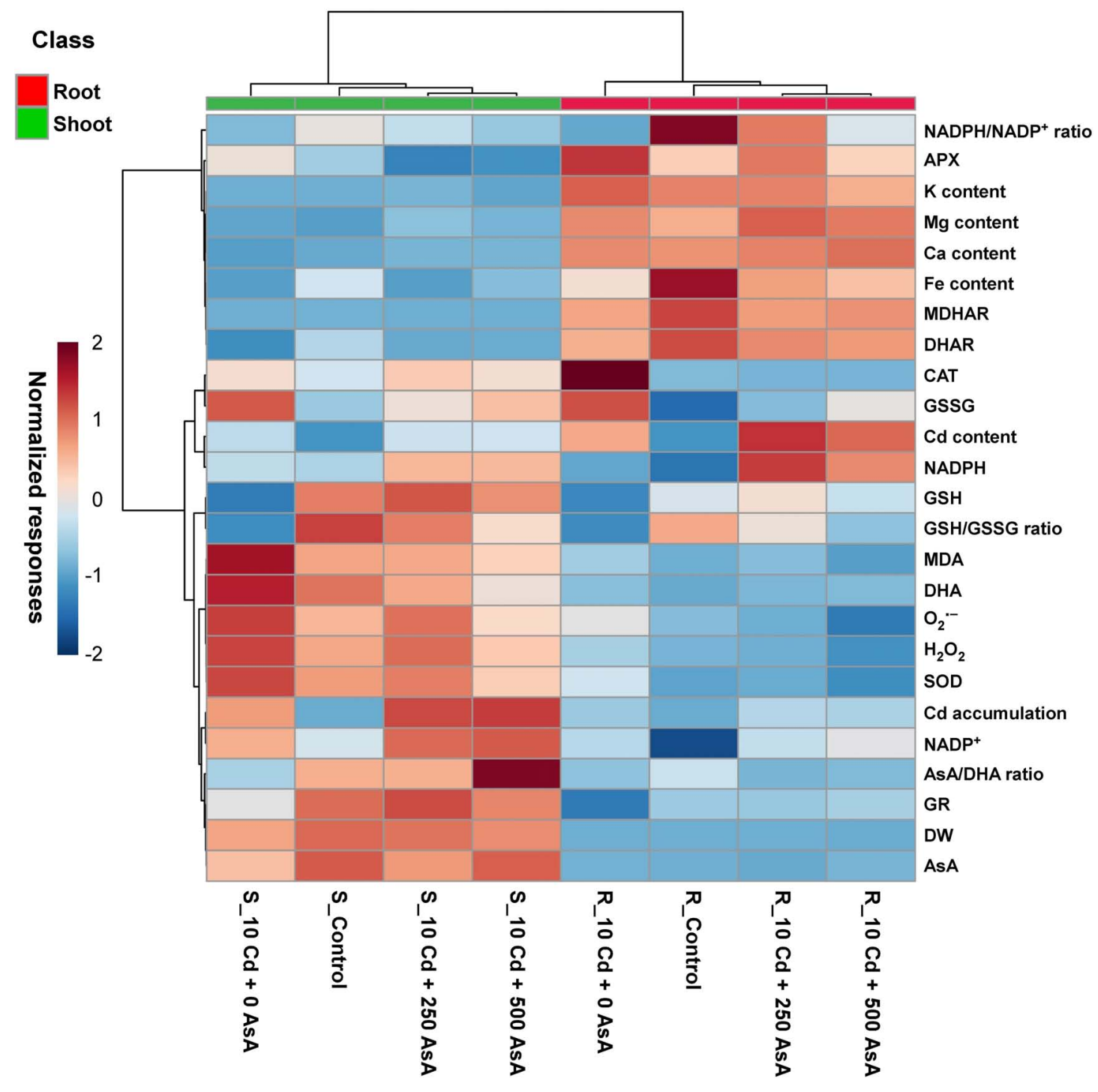

FIGURE 6 | Heatmap analysis of Pearson's correlation coefficient ( $r$ ) for the targeted metabolites of reactive oxygen species (ROS) and ascorbate (AsA)/glutathione (GSH)/nicotinamide adenine dinucleotide phosphate (NADPH) redox status in cadmium (Cd)-stressed seedlings with or without AsA application. R, root; S, shoot. The numbers after $\mathrm{Cd}$ of the code names indicate the AsA level $\left(0,250\right.$, or $\left.500 \mathrm{mg} \mathrm{kg}^{-1}\right)$. Red and blue indicate positive and negative normalized responses between the targeted metabolites.

AsA treatment under Cd stress conditions were clearly segregated (Figure 7). Furthermore, the effects of AsA treatment under Cd stress conditions were more apparent in the shoot than in the root (Figure 7). In the PCA, the Cd-only treatment had the most divergent responses from those of the untreated control regardless of organ type. AsA addition treatments appeared closer in the plot to the control than that to the Cd-only treatment (Figure 7).

\section{DISCUSSION}

Many studies have reported that the contamination of agricultural lands by excess $\mathrm{Cd}$ adversely affects sustainable crop productivity. Cd toxicity negatively affects photosynthesis by reducing chlorophyll content, which adversely influences general plant growth and development by disrupting vital metabolic processes (Kim et al., 2008; Hong et al., 2013; Jan et al., 2015; Khan et al., 2015; Jung et al., 2016, 2017, 2018b; Farooq et al., 2018). Recently, some studies have demonstrated that the exogenous application of sulfur (Khan et al., 2015; Jung et al., 2017; Tian et al., 2017), glutathione (Chen et al., 2010; Mostofa et al., 2014; Kim et al., 2017; Jung et al., 2019) or ascorbate (Chen et al., 2017; Jung et al., 2018a; Semida et al., 2018; Zhang et al., 2019) may alleviate different heavy metal stresses.

In this study, we have shown that AsA alleviates the heavy metal stress induced by $\mathrm{Cd}$, thereby contributing to reversing the negative effects of $\mathrm{Cd}$ on plant growth and development 


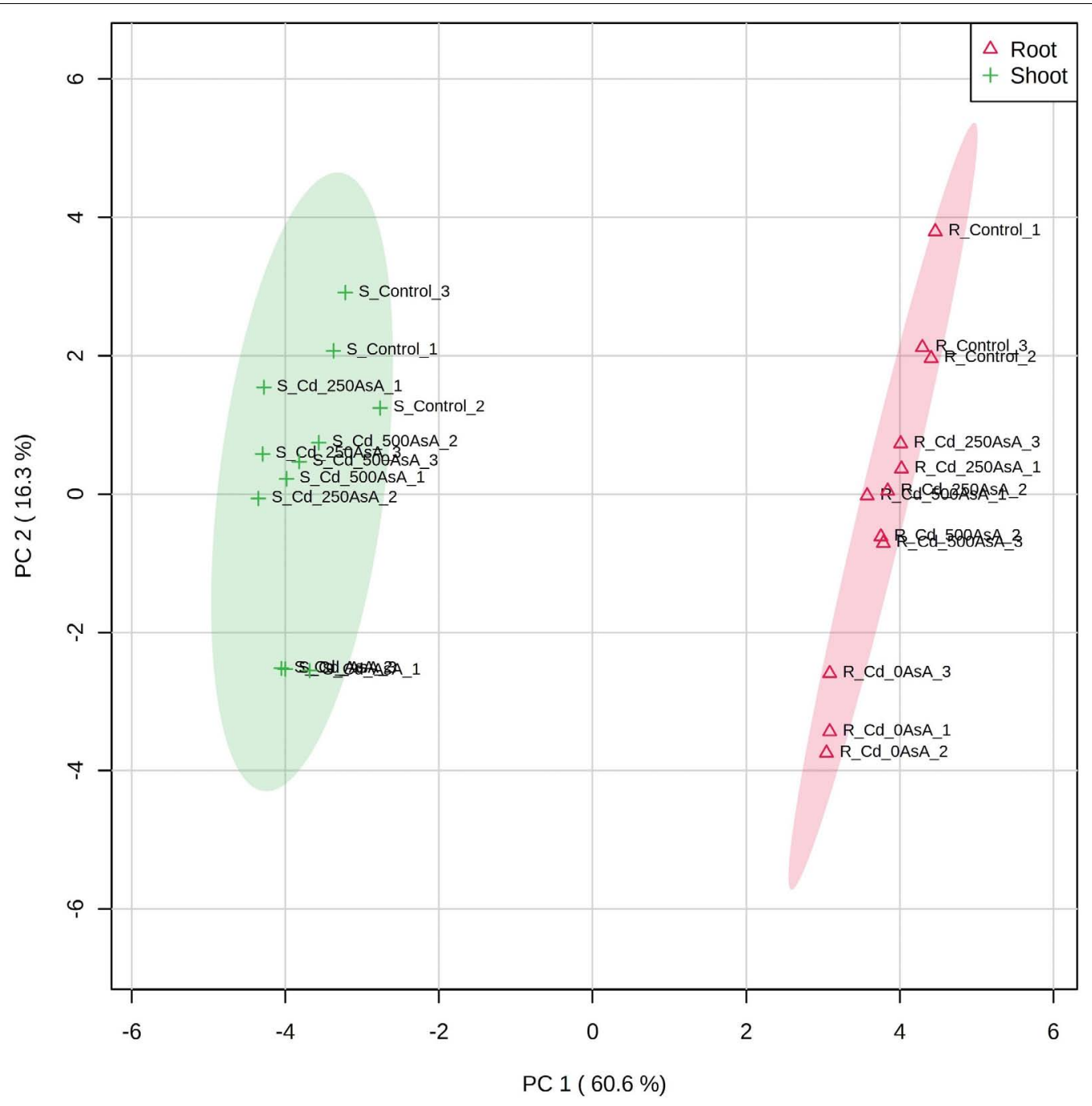

FIGURE 7 | Principal component analysis (PCA) scores plot of the targeted metabolites of reactive oxygen species (ROS) and ascorbate (AsA)/glutathione $(\mathrm{GSH}) /$ nicotinamide adenine dinucleotide phosphate (NADPH) redox status in the roots $(\Delta)$ and shoots $(+)$ of seedlings treated with different AsA levels. R, root; $\mathrm{S}$, shoot. The numbers after cadmium (Cd) in the code names indicate the AsA level $\left(0,250\right.$, or $\left.500 \mathrm{mg} \mathrm{AsA} \mathrm{kg}^{-1}\right)$. The last digit indicates which of the three replicates is shown.

and increasing plant tolerance and accumulation of $\mathrm{Cd}$ by ameliorating its phytotoxic effects. For instance, shoot FW and DW of Cd-stressed oilseed rape seedlings were significantly reduced by $\mathrm{Cd}$ treatment. However, application of AsA to Cdexposed oilseed rape seedlings significantly alleviated the negative effects of $\mathrm{Cd}$ on the shoot biomass of oilseed rape plants (Table 1). Significantly higher $\mathrm{Cd}$ contents were observed in the roots and shoots of Cd-stressed oilseed rape seedlings treated with AsA than in those treated with $\mathrm{Cd}$ alone (Figure 1A). Many studies have been reported that $\mathrm{Cd}$ uptake and/or accumulation varies by plant species and organs (Chen et al., 2010; Wu et al., 2015; Jung et al., 2016, 2018b). In this study, we revealed that AsA application alleviates the overall phytotoxicity of $\mathrm{Cd}$ and increases Cd uptake and accumulation both in roots and shoots of the oilseed rape plant (Figure 1). This shows that AsA promoted $\mathrm{Cd}$ accumulation in the roots and increased $\mathrm{Cd}$ translocation to the plants because it seems to be critical in reducing the oxidative damage induced by Cd.

$\mathrm{Cd}$ exposure induces the production of ROS and a cascade of toxic effects resulting from oxidative stress. As a non-essential heavy metal, $\mathrm{Cd}$ can play a key role as a cofactor in Fenton reactions by replacing the essential ions of metalloproteins (Peroza et al., 2009; Singh et al., 2016). The altered reaction modifies essential nutrient uptake (Figure 2) and induces lipid peroxidation in the plant cell via the production of ROS, $\mathrm{O}_{2}{ }^{--}, \mathrm{H}_{2} \mathrm{O}_{2}$, and $\mathrm{OH} \cdot$, thereby resulting in cell membrane destruction (Figure 3) (Ahmad et al., 2016; Loix et al., 2017). Moreover, it disturbs ion and redox homeostasis in cell metabolic pathways (Gayomba et al., 2013; Asgari Lajayer et al., 2017). This study demonstrated that $\mathrm{Cd}$ induced oxidative stresses by the overproduction of $\mathrm{O}_{2}{ }^{--}$(Figure 3A) and $\mathrm{H}_{2} \mathrm{O}_{2}$ (Figure 3B) in the roots and shoots of oilseed rape seedlings. This is in 
agreement with the previous findings of Jung et al. (2017) and Hasanuzzaman et al. (2017).

However, AsA application to Cd-stressed oilseed rape seedlings decreased the level of $\mathrm{O}_{2}{ }^{-}$and $\mathrm{H}_{2} \mathrm{O}_{2}$ and thus played a critical role in alleviating the oxidative stress caused by Cd (Figures $3 \mathbf{A}, \mathbf{B}$ ). Increased levels of ROS lead to lipid peroxidation, causing membrane damage and the malfunctioning of ion transporters (Gayomba et al., 2013; Loix et al., 2017). $\mathrm{Cd}$ increases the MDA level, which is as an indicator of lipid peroxidation under $\mathrm{Cd}$ phytotoxicity (Hasanuzzaman et al., 2017). MDA production in both organs significantly increased in the Cd-stressed seedlings (Figure 3C). However, exogenous application of AsA to Cd-stressed seedlings significantly reduced Cd-induced production of $\mathrm{O}_{2}{ }^{-}$(Figure 3A), $\mathrm{H}_{2} \mathrm{O}_{2}$ (Figure 3B), and MDA (Figure 3C) compared to that of $\mathrm{Cd}$ alone treatment. AsA-mediated alleviation in oxidative stress is through its antioxidant effect in the non-enzymatic (Figure 4) and enzymatic (Figure 5) antioxidant scavenging systems, thus, leading to declining MDA production, increasing $\mathrm{Cd}$ accumulation, and altering the antioxidant defense system in a manner associated with relieving an excessive level of ROS.

In plants, the antioxidants AsA and GSH play a critical role in reducing the oxidative stress induced by heavy metals. Plants can alleviate Cd-induced oxidative stress either enzymatically with antioxidant or redox enzymes or non-enzymatically by employing antioxidant metabolites as electron scavengers (Gill and Tuteja, 2010; Shekhawat et al., 2010; Foyer and Noctor, 2011); both systems for mitigating oxidative stress are essential for maintaining cellular redox homeostasis and in protecting the function of membrane systems (Yan et al., 2015; Hasanuzzaman et al., 2017). AsA plays a critical role in ROS scavenging and redox regulation under heavy metal stress (Chao et al., 2010; Loix et al., 2017; Jung et al., 2018a; Semida et al., 2018; Zhang et al., 2019). GSH is an antioxidant with a sulfhydryl group (-SH) that is important in scavenging the ROS produced by heavy metals (Srivastava et al., 2014; Singh et al., 2015; Kumar and Trivedi, 2018). Therefore, AsA and GSH directly play pivotal roles as antioxidants associated with scavenging ROS and regulating the critical components of the antioxidant defense system (Akram et al., 2017; Kim et al., 2017; Jung et al., 2018a, 2019).

Plant antioxidant content and redox status are therefore informative for understanding plant tolerance to heavy metal stress. For example, it is known that the AsA, GSH, and NADPH levels and their redox ratios are the main factors influencing plant survival under various abiotic stress conditions (Mostofa et al., 2014; Jung et al., 2019). In our study, Cd-exposed plants did not exhibit changes in their NADPH levels, but their AsA and GSH levels significantly decreased in comparison to the untreated plants. Moreover, there was an increase in the levels of DHA, GSSG, and NADP ${ }^{+}$, while the AsA/DHA, GSH/GSSG, and NADPH/NADP ${ }^{+}$ratios concurrently declined (Figure 4).

Our results are consistent with those of previous studies on the effects of $\mathrm{Cd}$ stress on plants and the potential for AsA to alleviate $\mathrm{Cd}$-induced oxidative stress. Cd uptake caused oxidative stress, resulting in increased generation of ROS and lipid peroxidation, as similarly reported in many studies (Gill and Tuteja, 2010; Shekhawat et al., 2010; Foyer and Noctor, 2011;
Hasanuzzaman et al., 2017). The present study demonstrates that the oxidative stress induced by $\mathrm{Cd}$ in oilseed rape seedlings was correlated further with the redox status of AsA, GSH, and $\mathrm{NADPH}$ (Figure 4). However, AsA application improved the AsA, GSH, and NADPH levels and AsA/DHA, GSH/GSSG, and $\mathrm{NADPH} / \mathrm{NADP}^{+}$ratios, which might enhance the activities of the AsA-GSH-NADPH cycle to overcome Cd toxicity (Figure 4). Consistent with our results, Chao et al. (2010) and Jung et al. (2018a) reported that exogenous AsA treatment alleviated Cdand As-induced ROS, lowered lipid peroxidation, increased AsA levels, and helped maintain cellular redox homeostasis in rice seedlings, respectively.

Herein, we have presented an antioxidant mechanism to increase Cd uptake and accumulation in oilseed rape seedlings by alleviating $\mathrm{Cd}$-induced oxidative stress and maintaining the homeostasis of the AsA-GSH-NADPH cycle. Rice seedlings subjected to heavy metal stress exhibited increases in SOD, CAT, and APX activities concomitant with regulation of the enzymes, which are the key antioxidant defense and/or redox regulation pathway leading to synthesis of antioxidants, AsA and GSH and the redox metabolite, NADPH. On the other hand, MDHAR, DHAR, and GR activities often decrease in response to heavy metal exposure (Jung et al., 2018a, 2019). These components in the antioxidant defense system remove ROS, thereby contributing to sustaining the cellular redox status (Sharma et al., 2017).

Our results have demonstrated that relatively low AsA and high DHA levels are maintained by the increase of APX activity or reduction of DHAR activity, thus decreasing the AsA/DHA redox status under Cd-stressed conditions. A low AsA/DHA redox status increases the GSSG level and decreases the GSH/GSSG ratio by regulating DHAR. Under the conditions of Cd stress, GR also plays a critical role in changing the GSH/GSSG ratio by catalyzing the reduction of GSSG to GSH (Figures 4, 5). Simultaneously, GR is downregulated by a reduction in $\mathrm{Cd}$-induced oxidative stress, thereby increasing $\mathrm{NADP}^{+}$content (Chou et al., 2012). This reaction could decrease the NADPH/NADP ${ }^{+}$redox ratio.

However, applying exogenous AsA to Cd-stressed oilseed rape seedlings markedly decreases the DHA but increases the GSH levels through the downregulation of APX; this increases the AsA/DHA redox state. A high AsA/DHA redox status reduces the GSSG level and enhances the GSH/GSSG ratio by upregulating DHAR. Concomitantly, GR is upregulated by a decrease in Cdinduced oxidative stress with exogenous AsA application, thus increasing the GSH level. This, in turn, increases the GSH/GSSG redox ratio (Figures 4, 5). On the other hand, although $\mathrm{NADPH}$ level was increased in Cd-stressed plants with AsA treatment, $\mathrm{NADP}^{+}$also showed high levels of production, so there was no significant change in NADPH/NADP ${ }^{+}$ratio (Figure 4).

Figure 8 provides a simple proposed mechanism for increasing $\mathrm{Cd}$ accumulation in oilseed rape plants by alleviating Cd-induced oxidative stress and sustaining homeostasis of the AsA-GSH-NADPH cycle. AsA application to Cd-stressed oilseed rape plants significantly decreased the production of $\mathrm{O}_{2}{ }^{--}, \mathrm{H}_{2} \mathrm{O}_{2}$, and MDA relative to that observed in plants subjected to $\mathrm{Cd}$ treatment alone (Figure $\mathbf{8 B}$ ). As shown here, the proposed 

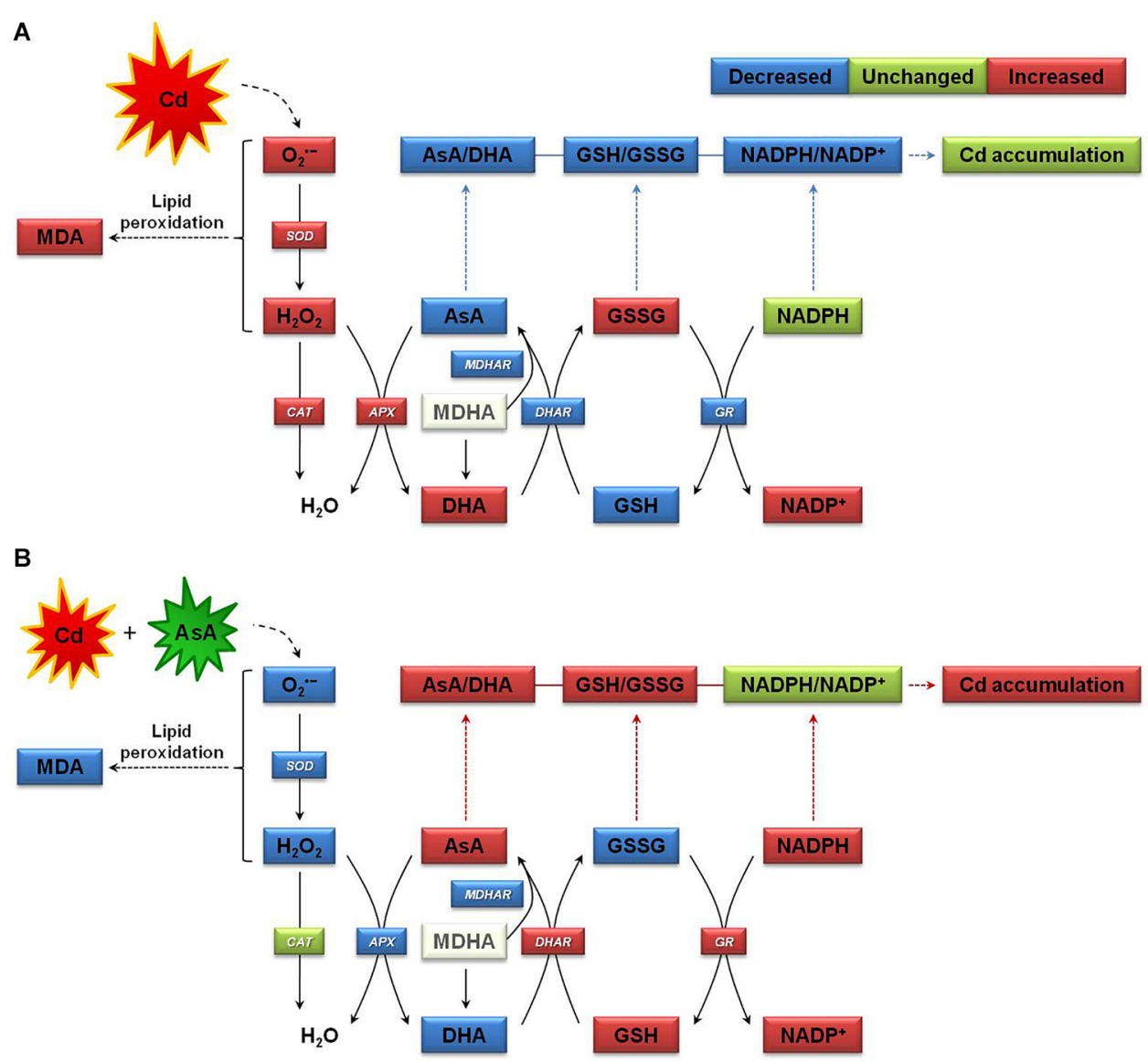

FIGURE 8 | Proposed mechanism of increase in cadmium (Cd) accumulation in oilseed rape seedlings by mitigating Cd-induced oxidative stress and sustaining homeostasis of the ascorbate (AsA)-glutathione (GSH)-nicotinamide adenine dinucleotide phosphate (NADPH) cycle, which involves three interdependent redox couples, AsA/DHA, GSH/GSSG, and NADPH/NADP ${ }^{+}$. (A) The Cd-stressed plant growth state and (B) the Cd-exposed and AsA-treated plant growth state. APX, ascorbate peroxidase; AsA, ascorbate (reduced form); DHA, dehydroascorbate (oxidized form); AsA/DHA, AsA/DHA redox ratio; CAT, catalase; DHAR, dehydroascorbate reductase; GR, glutathione reductase; GSH, glutathione (reduced form); GSSG, glutathione disulfide (oxidized form); GSH/GSSG, GSH/GSSG redox ratio; MDA, malondialdehyde (a chemical index of lipid peroxidation); MDHA, monodehydroascorbate; MDHAR, monodehydroascorbate reductase; NADPH (reduced form) and $\mathrm{NADP}^{+}$(oxidized form), nicotinamide adenine dinucleotide phosphate; SOD, superoxide dismutase.

mechanism indicates that AsA application to plants under Cd exposure promoted the AsA-GSH-NADPH cycle activities, thereby contributing to increasing $\mathrm{Cd}$ accumulation in the plants and improving the ROS scavenging system, which increased AsA-induced Cd resistance in oilseed rape plants.

\section{CONCLUSION}

Our results clearly indicate that exogenous AsA contributes to the alleviation of Cd-induced oxidative stress in oilseed rape plants by a concomitant promotion of the components of the antioxidant scavenging defense system. Our results also demonstrate that exogenous AsA application to oilseed rape seedlings under $\mathrm{Cd}$ stress significantly alleviated the overall $\mathrm{Cd}$ toxicity by regulating the homeostasis of the AsA-GSH-NADPH cycle, which reestablishes the cellular redox status. However, largescale field experiments should be highly valuable in developing a phytoremediation and/or sustainable agriculture production system for especially Cd-contaminated lands. Therefore, the results reported here provide invaluable insights into the critical role of AsA in regulating the AsA-GSH-NADPH cycle system and, as a result, the Cd uptake, accumulation, and resistance of oilseed rape plants.

\section{DATA AVAILABILITY STATEMENT}

The original contributions presented in the study are included in the article/supplementary material, further inquiries can be directed to the corresponding author.

\section{AUTHOR CONTRIBUTIONS}

$\mathrm{HJ}$ designed the experiment. $\mathrm{HJ}$ and $\mathrm{B}-\mathrm{RL}$ performed the experiment. HJ, B-RL, M-JC, E-JL, T-GL, G-BJ, M-SK, and JL analyzed the data and provided constructive comments and 
discussion on the manuscript. HJ and JL wrote, revised, and corrected the manuscript. All authors contributed to the article and approved the submitted version.

\section{FUNDING}

This study was supported by the "Cooperative Research Program for Agriculture Science \& Technology Development (Project No. PJ014360)," Rural Development Administration, Korea.

\section{REFERENCES}

Ahmad, P., Abdel Latef, A. A., Abd Allah, E. F., Hashem, A., Sarwat, M., Anjum, N. A., et al. (2016). Calcium and potassium supplementation enhanced growth, osmolyte secondary metabolite production, and enzymatic antioxidant machinery in cadmium-exposed chickpea (Cicer arietinum L.). Front. Plant Sci. 7:513. doi: 10.3389/fpls.2016.00513

Ahmad, P., Sarwat, M., Bhat, N. A., Wani, M. R., Kazi, A. G., and Tran, L. P. (2015). Alleviation of cadmium toxicity in Brassica juncea L. (Czern. \& Coss.) by calcium application involves various physiological and biochemical strategies. PLoS One 10:e0114571. doi: 10.1371/journal.pone.0114571

Akram, N. A., Shafiq, F., and Ashraf, M. (2017). Ascorbic acid-a potential oxidant scavenger and its role in plant development and abiotic stress tolerance. Front. Plant Sci. 8:613. doi: 10.3389/fpls.2017.00613

Ali, B., Qian, P., Jin, R., Ali, S., Khan, M., Aziz, R., et al. (2014). Physiological and ultra-structural changes in Brassica napus seedlings induced by cadmium stress. Biol. Plant. 58, 131-138. doi: 10.1007/s10535-013-0358-5

Asgari Lajayer, B., Ghorbanpour, M., and Nikabadi, S. (2017). Heavy metals in contaminated environment: destiny of secondary metabolite biosynthesis, oxidative status and phytoextraction in medicinal plants. Ecotoxicol. Environ. Saf. 145, 377-390. doi: 10.1016/j.ecoenv.2017.07.035

Buege, J. A., and Aust, S. D. (1978). Microsomal lipid peroxidation. Methods Enzymol. 52, 302-310.

Chao, Y. Y., Hong, C. Y., and Kao, C. H. (2010). The decline in ascorbic acid content is associated with cadmium toxicity of rice seedlings. Plant Physiol. Biochem. 48, 374-381. doi: 10.1016/j.plaphy.2010. 01.009

Chen, F., Wang, F., Wu, F., Mao, W., Zhang, G., and Zhou, M. (2010). Modulation of exogenous glutathione in antioxidant defense system against Cd stress in the two barley genotypes differing in Cd tolerance. Plant Physiol. Biochem. 48, 663-672. doi: 10.1016/j.plaphy.2010.05.001

Chen, G. X., and Asada, K. (1989). Ascorbate peroxidase in tea leaves: occurrence of two isozymes and the differences in their enzymatic and molecular properties. Plant Cell Physiol. 30, 987-998.

Chen, K., Zhang, M., Zhu, H., Huang, M., Zhu, Q., Tang, D., et al. (2017). Ascorbic acid alleviates damage from heat stress in the photosystem II of tall fescue in both the photochemical and thermal phases. Front. Plant Sci. 8:1373.

Chong, J., Soufan, O., Li, C., Caraus, I., Li, S., Bourque, G., et al. (2018). MetaboAnalyst 4.0: towards more transparent and integrative metabolomics analysis. Nucl. Acids Res. 46, 486-494.

Chou, T. S., Chao, Y. Y., and Kao, C. H. (2012). Involvement of hydrogen peroxide in heat shock- and cadmium-induced expression of ascorbate peroxidase and glutathione reductase in leaves of rice seedlings. J. Plant Physiol. 169, 478-486. doi: 10.1016/j.jplph.2011.11.012

Elstner, E. F., and Heupel, A. (1976). Inhibition of nitrite formation from hydroxylammonium-chloride: a simple assay for superoxide dismutase. Anal. Biochem. 70, 616-620. doi: 10.1016/0003-2697(76)90488-7

Farooq, M., Hussain, M., Usman, M., Farooq, S., Alghamdi, S. S., and Siddique, H. M. (2018). Impact of abiotic stresses on grain composition and quality in food legumes. J. Agric. Food Chem. 66, 8887-8897. doi: 10.1021/acs.jafc. 8 b02924

Foyer, C. H., and Noctor, G. (2011). Ascorbate and glutathione: the heart of the redox hub. Plant Physiol. 155, 2-18. doi: 10.1104/pp.110.16 7569

\section{ACKNOWLEDGMENTS}

We would like to thank Jung-Kyo Cho, Min-Hae Jung, Su-Min Lee, and Eun-A Kim, National Institute of Agricultural Science, Korea, for supporting the greenhouse experiments and heavy metal analysis. We would also like to thank to Md Tabibul Islam, Ph.D., and Van Hien La, Ph.D., at the Laboratory of Grassland Science, Department of Animal Science, Chonnam National University, Korea, for their assistance in measuring the contents of ROS and antioxidants.

Gall, J. E., and Rajakaruna, N. (2013). "The Physiology, Functional Genomics, and Applied Ecology of Heavy Metal-tolerant Brassicaceae," in Brassicaceae: Characterization, Functional Genomics and Health Benefits, Vol. 2013, ed. M. Lang, (Hauppauge, NY: Nova Science Publishers), 121-148.

Gayomba, S. R., Jung, H. I., Yan, J., Danku, J., Rutzke, M. A., Bernal, M., et al. (2013). The CTR/COPT-dependent copper uptake and SPL7-dependent copper deficiency responses are required for basal cadmium tolerance in A. thaliana. Metallomics 5, 1262-1275. doi: 10.1039/c3mt00111c

Gill, S. S., and Tuteja, N. (2010). Reactive oxygen species and antioxidant machinery in abiotic stress tolerance in crop plants. Plant Physiol. Biochem. 48, 909-930. doi: 10.1016/j.plaphy.2010.08.016

Hasanuzzaman, M., Nahar, K., Anee, T. I., and Fujita, M. (2017). Exogenous silicon attenuates cadmium-induced oxidative stress in Brassica napus L. by modulating AsA-GSH pathway and glyoxalase system. Front. Plant Sci. 8:1061. doi: 10.3389/fpls.2017.01061

Hong, C. O., Kim, Y. G., Lee, S. M., Park, H. C., Kim, K. K., Son, H. J., et al. (2013). Liming effect on cadmium immobilization and phytoavailability in paddy soil affected by mining activity. Kor. J. Environ. Agric. 32, 1-8. doi: 10.5338/kjea. 2013.32.1.1

Hossain, M. A., Nakano, Y., and Asada, K. (1984). Monodehydroascorbate reductase in spinach chloroplasts and its participation in the regeneration of ascorbate for scavenging hydrogen peroxide. Plant Cell Physiol. 25, 385-395.

Jan, A. T., Azam, M., Siddiqui, K., Ali, A., Choi, I., and Haq, Q. M. (2015). Heavy metals and human health: mechanistic insight into toxicity and counter defense system of antioxidants. Int. J. Mol. Sci. 16, 29592-29630. doi: 10.3390/ ijms 161226183

Jana, S., and Choudhuri, M. A. (1982). Glycolate metabolism of three submerged aquatic angiosperms during ageing. Aquat. Bot. 12, 345-354. doi: 10.1016/ 0304-3770(82)90026-2

Jung, H. I., Chae, M. J., Kim, S. J., Kong, M. S., Kang, S. S., Lee, D. B., et al. (2015). Effects of cadmium and arsenic on physiological responses and copper and zinc homeostasis of rice. Kor. J. Soil Sci. Fert. 48, 397-403. doi: 10.7745/kjssf.2015. 48.5.397

Jung, H. I., Chae, M. J., Kong, M. S., Kang, S. S., and Kim, Y. H. (2016). Effect of rice straw compost on cadmium transfer and metal-ions distribution at different growth stages of soybean. Kor. J. Soil Sci. Fert. 49, 644-650. doi: 10.7745/kjssf.2016.49.6.644

Jung, H. I., Kong, M. S., Chae, M. J., Lee, E. J., Jung, G. B., and Kim, Y. H. (2018a). Effect of ascorbate on the arsenic uptake, ROS-scavenging capacity, and antioxidant homeostasis in rice. Kor. J. Soil Sci. Fert. 51, 90-100.

Jung, H. I., Kong, M. S., Lee, E. J., Jung, G. B., and Kim, Y. H. (2018b). Growthinhibition patterns and bioconcentration profiles in cadmium-stressed oilseed rape (Brassica napus L.). Kor. J. Soil Sci. Fert. 51, 159-168.

Jung, H. I., Kong, M. S., Lee, B. R., Kim, T. H., Chae, M. J., Lee, E. J., et al. (2019). Exogenous glutathione increases arsenic translocation into shoots and alleviates arsenic-induced oxidative stress by sustaining ascorbate-glutathione homeostasis in rice seedlings. Front. Plant Sci. 10:1089. doi: 10.3389/fpls.2019. 01089

Jung, H. I., Lee, B. R., Chae, M. J., Kong, M. S., Lee, C. H., Kang, S. S., et al. (2017). Sulfur alleviates cadmium toxicity in rice (Oryza sativa L.) seedlings by altering antioxidant levels. J. Crop Sci. Biotechnol. 20, 213-220. doi: 10.1007/s12892017-0072-0

Khan, A., Khan, S., Khan, M. A., Qamar, Z., and Waqas, M. (2015). The uptake and bioaccumulation of heavy metals by food plants, their effects on plants 
nutrients, and associated health risk: a review. Environ. Sci. Pollut. Res. Int. 22, 13772-13799. doi: 10.1007/s11356-015-4881-0

Kim, W. I., Park, B. J., Park, S. W., Kim, J. K., Kwon, O. K., Jung, G. B., et al. (2008). Relationship between fraction of $\mathrm{Cd}$ in paddy soils near closed mine and $\mathrm{Cd}$ in polished rice cultivated on the same fields. Kor. J. Soil Sci. Fert. 41, 184-189.

Kim, Y. O., Bae, H. J., Cho, E., and Kang, H. (2017). Exogenous glutathione enhances mercury tolerance by inhibiting mercury entry into plant cells. Front. Plant Sci. 8:683. doi: 10.3389/fpls.2017.00683

Kruger, N. J. (1994). The Bradford method for protein quantitation. Methods Mol. Biol. 32, 9-15. doi: 10.1385/0-89603-268-x:9

Kumar, S., and Trivedi, P. K. (2018). Glutathione S-transferases: role in combating abiotic stresses including arsenic detoxification in plants. Front. Plant Sci. 9:751. doi: 10.3389/fpls.2018.00751

Law, M. Y., Charles, S. A., and Halliwell, B. (1983). Glutathione and ascorbic acid in spinach (Spinacia oleracea) chloroplasts: the effect of hydrogen peroxide and of paraquat. Biochem. J. 210, 899-903. doi: 10.1042/bj2100899

Lee, B. R., Li, L. S., Jung, W. J., Jin, Y. L., Avice, J. C., Qurry, A., et al. (2009). Water deficit-induced oxidative stress and the activation of antioxidant enzymes in white clover leaves. Biol. Plant. 53, 505-510. doi: 10.1007/s10535-009-0091-2

Lee, B. R., Muneer, S., Park, S. H., Zhang, Q., and Kim, T. H. (2013). Ammonium-induced proline and sucrose accumulation, and their significance in antioxidative activity and osmotic adjustment. Acta Physiol. Plant. 35, 26552664. doi: 10.1007/s11738-013-1297-7

Lee, B. R., Zaman, R., Avice, J. C., Ourry, A., and Kim, T. H. (2016). Sulfur use efficiency is a significant determinant of drought stress tolerance in relation to photosynthetic activity in Brassica napus cultivars. Front. Plant Sci. 7:459. doi: $10.3389 /$ fpls.2016.00459

Loix, C., Huybrechts, M., Vangronsveld, J., Gielen, M., Keunen, E., and Cuypers, A. (2017). Reciprocal interactions between cadmium-induced cell wall responses and oxidative stress in plants. Front. Plant Sci. 8:1867. doi: 10.3389/fpls.2017. 01867

Meister, A., and Anderson, M. E. (1983). Glutathione. Annu. Rev. Biochem. 52, 711-760.

Meng, H., Hua, S., Shamsi, I. H., Jilani, G., Li, Y., and Jiang, L. (2009). Cadmiuminduced stress on the seed germination and seedling growth of Brassica napus L., and its alleviation through exogenous plant growth regulators. Plant Growth Regul. 58, 47-59. doi: 10.1007/s10725-008-9351-y

Meuwly, P., and Rauser, W. E. (1992). Alteration of thiol pools in roots and shoots of maize seedlings exposed to cadmium: adaptation and developmental cost. Plant Physiol. 99, 8-15. doi: 10.1104/pp.99.1.8

Mostofa, M. G., Seraj, Z. I., and Fujita, M. (2014). Exogenous sodium nitroprusside and glutathione alleviate copper toxicity by reducing copper uptake and oxidative damage in rice (Oryza sativa L.) seedlings. Protoplasma 251, 1373 1386. doi: 10.1007/s00709-014-0639-7

Nakano, Y., and Asada, K. (1981). Hydrogen peroxide is scavenged by ascorbatespecific peroxidase in spinach chloroplasts. Plant Cell Physiol. 22, 867-880.

Peroza, E. A., Kaabi, A. A., Meyer-Klaucke, W., Wellenreuther, G., and Freisinger, E. (2009). The two distinctive metal ion binding domains of the wheat metallothionein Ec-1. J. Inorg. Biochem. 103, 342-353. doi: 10.1016/j.jinorgbio. 2008.11.008

Queval, G., and Noctor, G. (2007). A plate reader method for the measurement of NAD, NADP, glutathione, and ascorbate in tissue extracts: application to redox profiling during Arabidopsis rosette development. Anal. Biochem. 363, 58-69. doi: $10.1016 /$ j.ab.2007.01.005
Rao, M. V., Paliyath, G., and Ormrod, D. P. (1996). Ultraviolet B- and ozoneinduced biochemical changes in antioxidant enzymes of Arabidopsis thaliana. Plant Physiol. 110, 125-136. doi: 10.1104/pp.110.1.125

Semida, W. M., Hemida, K. A., and Rady, M. M. (2018). Sequenced ascorbateproline-glutathione seed treatment elevates cadmium tolerance in cucumber transplants. Ecotoxicol. Environ. Saf. 154, 171-179. doi: 10.1016/j.ecoenv.2018. 02.036

Sharma, S., Anand, G., Singh, N., and Kapoor, R. (2017). Arbuscular mycorrhiza augments arsenic tolerance in wheat (Triticum aestivum L.) by strengthening antioxidant defense system and thiol metabolism. Front. Plant Sci. 8:906. doi: 10.3389/fpls.2017.00906

Shekhawat, G. S., Verma, K., Jana, S., Singh, K., Teotia, P., and Prasad, A. (2010). In vitro biochemical evaluation of cadmium tolerance mechanism in callus and seedlings of Brassica juncea. Protoplasma 239, 31-38. doi: 10.1007/s00709-0090079-y

Singh, S., Parihar, P., Singh, R., Singh, V. P., and Prasad, M. (2016). Heavy metal tolerance in plants: role of transcriptomics, proteomics, metabolomics, and ionomics. Front. Plant Sci. 6:1143.

Singh, V. P., Singh, S., Kumar, J., and Prasad, S. M. (2015). Investigating the roles of ascorbate-glutathione cycle and thiol metabolism in arsenate tolerance in ridged Luffa seedlings. Protoplasma 252, 1217-1229. doi: 10.1007/s00709-0140753-6

Srivastava, R. K., Pandey, P., Rajpoot, R., Rani, A., and Dubey, R. S. (2014). Cadmium and lead interactive effects on oxidative stress and antioxidative responses in rice. Protoplasma 251, 1047-1065. doi: 10.1007/s00709-0140614-3

Tian, M., Hui, M., Thannhauser, T. W., Pan, S., and Li, L. (2017). Selenium-induced toxicity is counteracted by sulfur in broccoli (Brassica oleracea L. var. italica). Front. Plant Sci. 8:1425. doi: 10.3389/fpls.2017.01425

Wu, J., Guo, J., Hu, Y., and Gong, H. (2015). Distinct physiological responses of tomato and cucumber plants in silicon-mediated alleviation of cadmium stress. Front. Plant Sci. 6:453. doi: 10.3389/fpls.2015.00453

$\mathrm{Xu}, \mathrm{Y} ., \mathrm{Xu}, \mathrm{Q}$., and Huang, B. (2015). Ascorbic acid mitigation of water stressinhibition of root growth in association with oxidative defense in tall fescue (Festuca arundinacea Schreb.). Front. Plant Sci. 6:807. doi: 10.3389/fpls.2015. 00807

Yan, H., Filardo, F., Hu, X., Zhao, X., and Fu, D. (2015). Cadmium stress alters the redox reaction and hormone balance in oilseed rape (Brassica napus L.) leaves. Environ. Sci. Pollut. Res. 23, 3758-3769. doi: 10.1007/s11356-015-5640-y

Zhang, K., Wang, G., Bao, M., Wang, L., and Xie, X. (2019). Exogenous application of ascorbic acid mitigates cadmium toxicity and uptake in Maize (Zea mays L.). Environ. Sci. Pollut. Res. Int. 26, 19261-19271. doi: 10.1007/s11356-019-05 265-0

Conflict of Interest: The authors declare that the research was conducted in the absence of any commercial or financial relationships that could be construed as a potential conflict of interest.

Copyright (C) 2020 Jung, Lee, Chae, Lee, Lee, Jung, Kim and Lee. This is an open-access article distributed under the terms of the Creative Commons Attribution License (CC BY). The use, distribution or reproduction in other forums is permitted, provided the original author(s) and the copyright owner(s) are credited and that the original publication in this journal is cited, in accordance with accepted academic practice. No use, distribution or reproduction is permitted which does not comply with these terms. 